\title{
Cálculo da Alíquota de Contribuição Previdenciária Atuarialmente Equilibrada: Uma Aplicação ao Caso Brasileiro*
}

\author{
Fabio Giambiagi ${ }^{\dagger}$, Luís Eduardo Afonso ${ }^{\ddagger}$
}

\begin{abstract}
Contents: 1. Introdução; 2. Revisão da Literatura; 3. Álgebra do Equilíbrio Atuarial; 4. Parte Empírica; 5. 0 que os Resultados Permitem Inferir para o Brasil?; 6. Conclusões; A. Apêndice.
\end{abstract}

Keywords: Previdência Social; Alíquota de Contribuição; Equilíbrio Atuarial; Aposentadoria.

JEL Code: H55; H53.

O objetivo do artigo é calcular a alíquota de contribuição que iguala os valores presentes esperados das contribuições e aposentadorias em um sistema previdenciário. É desenvolvido um exercício teórico que possibilita o cálculo de tal alíquota, complementado por uma parte empírica, com dados brasileiros. A alíquota é calculada em diversas situações, abarcando diferenças de gênero, nível educacional e tipo de aposentadoria. A principal conclusão é que alíquotas da ordem de $31 \%$, como as existentes no Brasil, são excessivas para benefícios tipicamente previdenciários, como a aposentadoria por tempo de contribuição, mas insuficientes para a aposentadoria por idade, especialmente para as mulheres. The aim of this paper is to calculate the contribution tax rate that equals expected present values of contributions and old-age benefits in a social security system. A theoretical exercise is developed to generate an analytical formula for the contribution rate, complemented for an empirical analysis, using Brazilian data. The tax rate is calculated in diverse situations, including differences of gender, educational level and type of retirement. The main conclusion is that contribution rates around $31 \%$, as the observed in Brazil, are too high for retirement by contribution time, but insufficient for the retirement by age, especially for women.

\footnotetext{
* Os autores agradecem a Samuel de Abreu Pessôa e a Paulo Tafner pela leitura de versões anteriores desse texto. Os autores também são gratos aos comentários e sugestões feitos por dois pareceristas da RBE.

†Banco Nacional de Desenvolvimento Econômico e Social (BNDES). Av. Chile 100, 140 andar, sala 1405, Rio de Janeiro - RJ. CEP 20031-917. E-mail: fgiambia@bndes.gov.br

‡Departamento de Contabilidade e Atuária da FEA-USP. Av. Prof. Luciano Gualberto 908, Prédio FEA3, Sala 215 - Cidade Universitária, Butantã, São Paulo - SP. CEP 05508-900. E-mail: lafonso@usp.br
} 


\section{INTRODUÇÃO}

O Regime Geral de Previdência Social (RGPS) do Instituto Nacional do Seguro Social (INSS) pode ser classificado como um regime de repartição. Embora não sendo de capitalização, um regime pode ser de repartição e mesmo assim ser orientado por princípios de equilíbrio atuarial. A alíquota de contribuição previdenciária pode ser calculada de tal forma que o valor presente esperado do fluxo de contribuições durante a vida ativa de um indivíduo seja equivalente ao valor presente esperado do fluxo de benefícios recebidos após a passagem para a inatividade.

Este artigo se destina a discutir exatamente essa questão: qual deve ser uma alíquota previdenciária "correta" na Previdência Social brasileira? ${ }^{1}$ Muitas vezes, nos debates sobre o desequilíbrio previdenciário, mesmo no público especializado, aparece a idéia de que uma alíquota de $31 \%$ como a que prevalece no Brasil - $20 \%$ do empregador e $11 \%$ do empregado - seria mais do que suficiente para cobrir as aposentadorias se fosse utilizada em um sistema de capitalização. $\mathrm{O}$ artigo discutirá até que ponto isso é correto.

O tema insere-se no debate maior acerca da situação da Previdência Social no Brasil, objeto de preocupação há vários anos (Stephanes, 1998) e de duas reformas nas quais se investiu elevado capital político, nos Governos Cardoso e Lula. ${ }^{2}$ Entretanto, ambas as reformas revelaram-se insatisfatórias frente aos desafios colocados pelas perspectivas demográficas futuras (Cechin, 2002, Giambiagi et al., 2004). A questão da possível realização de uma terceira rodada de reformas está na agenda do país para a próxima década e, para tanto, saber se uma alíquota como a vigente é ou não adequada é fundamental para definir os contornos dessa reforma.

O artigo contém seis seções, incluindo esta breve introdução. Na seção dois é feita uma concisa revisão da literatura relevante. Na terceira seção é desenvolvido o modelo matemático empregado no cálculo da alíquota atuarial. A quarta seção traz as estimações realizadas e apresenta os resultados obtidos para as alíquotas atuarialmente equilibradas para as aposentadorias por tempo de contribuição para vários grupos de trabalhadores, de acordo com gênero, nível de escolaridade e tempo de contribuição. Com base na metodologia desenvolvida são feitos três exercícios adicionais, sendo o primeiro deles o cálculo da taxa de reposição previdenciária para as aposentadorias por tempo de contribuição e os dois seguintes referentes às aposentadorias por idade. A quinta seção trata da relevância dos resultados à luz dos parâmetros vigentes no Brasil. Por último, apresentam-se as conclusões e as recomendações de política, com base nos resultados obtidos.

O valor agregado que este texto pretende ter em relação a outros artigos com preocupação similar escritos no passado, como Giambiagi (1993) ou Oliveira et al. (1998) é o de atualizar o debate levando em conta os dispositivos associados à lei do fator previdenciário. ${ }^{3}$ Cálculos feitos no passado embutiam a hipótese de que aqueles que se aposentavam por tempo de contribuição o faziam com a média do histórico contributivo dos últimos três anos de contribuição. Ao modificar a legislação, no sentido de adotar não a média dos últimos 36 meses e sim da vida ativa do indivíduo, e multiplicando essa média por um fator que pode ser inferior a um para os casos de aposentadorias precoces, o valor presente dos benefícios pagos a partir da aposentadoria é menor. Isto porque tanto a média como o fator são inferiores aos que se utilizavam como referência antes da mudança legal introduzida na reforma de Fernando Henrique Cardoso. ${ }^{4}$ Consequentemente, as conclusões de artigos anteriores da literatura

\footnotetext{
${ }^{1} \mathrm{O}$ artigo trata especificamente dos casos de contribuintes do INSS e não dos servidores públicos, cujas regras são em parte diferentes.

${ }^{2}$ Para uma explicação sobre a reforma de Cardoso, ver Ornelas and Vieira (1999). Para uma análise sobre a reforma do Governo Lula, ver Souza et al. (2006).

${ }^{3} \mathrm{O}$ fator previdenciário é dado por $f=\frac{T c \cdot a}{E s}\left(1+\frac{I d . T c \cdot a}{100}\right)$. Nesta expressão $T c$ é o tempo de contribuição; $E s$ representa a expectativa de vida quando da aposentadoria, obtida com a idade $I d$. E $a$ é a alíquota de contribuição, para a qual se adota o valor de 0,31 .

${ }^{4}$ Antes dessa medida, a aposentadoria era calculada como se, na prática, o Fator Previdenciário fosse igual a um.
} 
ficaram desatualizadas à luz das novas regras. Essa lacuna é justamente a razão de ser do presente artigo.

\section{REVISÃO DA LITERATURA}

A literatura, tanto nacional, quanto internacional, não é muito pródiga em trabalhos em que se compute a alíquota de contribuição necessária para o equilíbrio atuarial em regimes previdenciários, sejam de repartição, sejam de capitalização. A maior parte dos artigos tem centrado seu foco no cálculo das taxas internas de retorno dos sistemas de previdência social (caso brasileiro) ou então, na análise das alíquotas marginais de contribuição, para outros países particularmente os EUA, como por exemplo, Feldstein and Samwick (1992). Uma exceção são os trabalhos de Feldstein (1995) e Geanakoplos et al. (2000), Feldstein and Samwick (1996), Feldstein and Samwick (2000) e Feldstein (2005), sendo que estes três últimos analisam os impactos oriundos da mudança de um sistema de repartição para um sistema total ou parcialmente fundado.

Roach and Ackerman (2005)avaliam que para manter o equilíbrio atuarial do Trust Fund da previdência norte-americana nos 75 anos seguintes a alíquota de contribuição somada (empregados e empregadores) deveria ser aumentada em 1,9 pontos percentuais, se os salários crescerem $1,1 \%$ a.a. No entanto se os salários se elevarem em apenas 0,6\% a.a., o aumento da alíquota deveria ser de 2,5 pontos percentuais. Outro cálculo, apresentado no OASDI Trustees Report (SSA, 2007:56) estima que o aumento na alíquota deve ser de 2,0 pontos percentuais. Ou, alternativamente, o mesmo resultado poderia ser obtido se os futuros benefícios tiverem seu valor esperado reduzido em $13 \%$.

Na República Tcheca, cálculos do governo (Ministry of Labour and Social Affairs - MLSA, 2001) mostram que embora a alíquota de contribuição vigente fosse de $26 \%$ (6,5\% para os empregados e $19,5 \%$ para os empregadores), a alíquota necessária deveria ser de $29 \%$. Esta conclusão é similar à de Schmaehl (2002), que analisa a tentativa de reforma previdenciária empreendida na Alemanha em 1997. Dadas as mudanças demográficas esperadas para os próximos anos, a alíquota necessária deveria passar dos $19 \%$ então vigentes para cerca de $24 \%$ em 2030 . Este resultado é corroborado por Börsch-Supan and Wilke (2003), que projetam uma alíquota necessária próxima a 26\% em 2042.

No Brasil um trabalho importante nessa linha foi desenvolvido por Oliveira and Maniero (1997). Os autores calculam as alíquotas de contribuição necessárias para o RGPS, tendo como parâmetros principais as idades de aposentadoria e de entrada no mercado de trabalho. Sua conclusão geral é que para a maioria das combinações das variáveis, as alíquotas necessárias seriam superiores às definidas pela legislação, dadas as regras então vigentes. No ano seguinte, McGreevey et al. (1998) fazem trabalho similar, desta vez analisando o Regime Próprio de Previdência Social (RPPS) dos funcionários públicos do Rio Grande do Sul. No caso particular das professoras, com entrada no mercado de trabalho aos 20 anos, período laboral de 25 anos e expectativa de vida até os 75 anos, a alíquota de contribuição deveria ser da ordem de 60\%. Oliveira et al. (1998) propõem um sistema previdenciário calcado nos princípios de equilíbrio atuarial. Os autores calculam com base nas regras então vigentes (anteriores à vigência do fator previdenciário) alíquotas justas para alguns grupos de trabalhadores. Seus resultados mostram, por exemplo, que com um taxa de desconto de 3\%, a alíquota atuarialmente justa para um homem que entrasse no mercado de trabalho aos 20 anos e se aposentasse aos 60, deveria ser de $20,1 \%$. Para os mesmos parâmetros, a alíquota justa para uma mulher seria de 22,9\%.

Fernandes and Gremaud (2004) têm sua atenção voltada para os servidores públicos federais, calculando as alíquotas de equilíbrio se as regras determinadas pela Emenda Constitucional 20 (EC20) tivessem vigorado desde sua entrada no mercado de trabalho. Seus resultados mostram que na média, para as diversas esferas de governo, as alíquotas deveriam ser superiores a 73\%. Fernandes and Narita (2005) fazem o mesmo cálculo para o INSS. Suas principais conclusões qualitativas são que as alíquotas de equilíbrio são mais altas para os trabalhadores com níveis de educação mais baixos e também para 
as regiões mais pobres do país. Estes resultados são bastante similares aos encontrados por Souza et al. (2006), para os quais as alíquotas do INSS (para benefícios previdenciários) situam-se na faixa de $20 \%$.

\section{3. ÁLGEBRA DO EQUILÍBRIO ATUARIAL}

Nesta seção, desenvolve-se a fórmula para calcular a alíquota de equilíbrio atuarial, começando pelo cálculo do valor presente dos fluxos de contribuições e, posteriormente das aposentadorias, para igualar ambas variáveis e chegar assim à alíquota que torna o valor presente das contribuições igual ao das aposentadorias a serem recebidas. ${ }^{5}$

\subsection{Valor presente do fluxo de contribuições}

O ponto de partida é a fórmula da soma de uma progressão geométrica $(S P G)$ finita com $n$ termos, primeiro termo $a_{1}$ e razão $q$ :

$$
S P G=a_{1} \cdot \frac{1-q^{n}}{1-q}
$$

Um sistema previdenciário está atuarialmente equilibrado se o valor presente esperado do fluxo das contribuições feitas por um indivíduo ao longo da sua vida ativa $(V P C)$ devidamente descontado a uma taxa de juros real $i$ é estritamente igual ao valor presente esperado do fluxo das aposentadorias $(V P A)$ a serem recebidas após a passagem para a inatividade. ${ }^{6}$

o termo $V P C$ pode ser igualado a uma $S P G$ na qual o primeiro termo é a primeira contribuição do indivíduo. ${ }^{7}$ Este corresponde ao resultado da multiplicação de uma alíquota de contribuição c pela renda $W$ para os períodos $1,2, \ldots, T$, em que $T$ é o número de anos de contribuição. Todos os cálculos, tanto das contribuições como das aposentadorias, são feitas em termos do valor presente do período 0 , imediatamente anterior ao do começo da vida ativa. ${ }^{8} 0$ cômputo é feito como se cada contribuição correspondesse a um depósito, capitalizado à taxa i até o período $T$ e trazido a valor presente de 0 . A contribuição correspondente à renda no primeiro período é capitalizada então por $T-1$ períodos; a do segundo por $T-2$ períodos e assim sucessivamente. Consequentemente, considerando que a renda cresce a uma taxa real $w$ em relação ao ano anterior, tem-se que:

$$
\begin{gathered}
V P C=\sum_{j=1}^{T} \frac{c W_{1}(1+w)^{j-1}(1+i)^{T-j}}{(1+i)^{T}} \\
V P C=\frac{c W_{1}(1+i)^{T-1}}{(1+i)^{T}}+\frac{c W_{1}(1+w)(1+i)^{T-2}}{(1+i)^{T}}+\ldots+\frac{c W_{1}(1+w)^{T-1}(1+i)^{T-T}}{(1+i)^{T}}
\end{gathered}
$$

Colocando alguns termos em evidência e dado se tratar de uma $S P G$, por analogia com (1), tendo $\frac{c W_{1}}{(1+i)}$ como primeiro termo e $\frac{(1+w)}{(1+i)}$ como razão, tem-se que (2) é igual a: ${ }^{9}$

\footnotetext{
${ }^{5}$ Esta seção segue de perto Giambiagi (1993) com algumas modificações.

${ }^{6}$ Não estão incluídos nos cálculos benefícios não programáveis como auxílio-doença ou aposentadoria por invalidez. Adota-se ainda a hipótese de que o falecimento do aposentado não implica pensão ao cônjuge ou dependentes.

${ }^{7}$ Supõe-se implicitamente que os fluxos monetários de renda e aposentadoria sejam anuais. Os resultados podem apresentar pequenas variações em relação ao uso de variáveis mensais, pela capitalização dos valores ao longo do ano, mas não alteram significativamente as conclusões. Raciocínio similar aplica-se à influência da inflação.

${ }^{8} \mathrm{O}$ valor presente das variáveis já sofre a incidência da taxa de juros referente ao primeiro período. Isto é, o valor presente da contribuição inicial é $\frac{c W_{1}}{(1+i)}$. Este é o termo correspondente a $a_{1}$ em (1) e que será utilizado nas equações seguintes.

${ }^{9} \mathrm{~A}$ equação 3 apresenta a priori uma indeterminação quando $i \rightarrow w$. Esse caso corresponde a $q \rightarrow 1$ na equação 1 . Pela aplicação direta da Regra de L'Hospital, prova-se que se $i \rightarrow w$ então em (3) tem-se $\lim _{i \rightarrow w} V P C=\frac{c W_{1} T}{(1+w)}$.
} 


$$
V P C=\frac{c W_{1}}{(i-w)}\left(\frac{(1+i)^{T}-(1+w)^{T}}{(1+i)^{T}}\right)
$$

\subsection{Valor presente do fluxo de aposentadorias}

O cálculo do valor presente do fluxo de aposentadorias $(V P A)$ a serem recebidas após a passagem para a inatividade obedece a uma lógica similar à que foi explicada no caso das contribuições. ${ }^{10} \mathrm{O}$ ponto de partida é a mesma equação (1) de uma $S P G$, onde se calcula o valor presente de um fluxo de pagamentos de valor real constante em moldes similares aos de uma "tabela Price", pagamentos esses correspondentes ao valor da aposentadoria $A$, desprezando, para efeitos do cálculo, a existência de inflação. Conceitualmente, o cálculo é idêntico ao que iguala o valor de um bem ao valor presente de um conjunto de prestações fixas. O valor presente do primeiro termo de (4) no cálculo de $V P A$ é igual ao valor de A descontado à taxa de juros $i$ já utilizada nas equações anteriores, sempre a preços do período 0 . Como a aposentadoria começa a ser recebida um período após $T$, último período de atividade, o fator de desconto $1+i$ deve ser elevado a $T+1$ para o cálculo do valor presente do primeiro fluxo de aposentadoria $A$ a preços do período 0, ou seja, $\frac{A}{(1+i)^{T+1}}$. O número de termos é $N$, correspondente ao número de períodos em que o indivíduo recebe sua aposentadoria após deixar de trabalhar, ou seja, o seu período de sobrevida. A razão dessa progressão geométrica é $\frac{1}{(1+i)}$.

$\mathrm{O}$ valor de $V P A$ a preços do período 0 é expresso por:

$$
\begin{gathered}
V P A=\sum_{j=T+1}^{T+N} \frac{A}{(1+i)^{j}} \\
V P A=\frac{A}{(1+i)^{T+1}}+\frac{A}{(1+i)^{T+2}}+\ldots+\frac{A}{(1+i)^{T+N}}
\end{gathered}
$$

que, por analogia com (1) pode ser escrita como

$$
V P A=\frac{A}{(1+i)^{T}} \frac{1}{i}\left(\frac{(1+i)^{N}-1}{(1+i)^{N}}\right)
$$

No RGPS a aposentadoria $A$ é determinada pela multiplicação do fator previdenciário $f$ pela média real dos $80 \%$ maiores salários de contribuição. Esta média pode ser definida, seguindo (1), como uma $S P G$ com razão $1+w$, com $0,8 T$ períodos, dividida pelo número de anos de contribuição $(80 \%$ de $T)$ considerados na referida média. Supondo uma taxa de crescimento anual constante $w$, o primeiro salário de contribuição do cálculo corresponde ao primeiro ano depois do período não utilizado de $20 \%$ de $T$, dado que a média é calculada com base em $80 \%$ das contribuições. Portanto, por (1), $A$ é dada por:

$$
A=f \frac{1}{0,8 T} W_{1}(1+w)^{0,2 T}\left(\frac{1-(1+w)^{0,8 T}}{1-(1+w)}\right)
$$

\footnotetext{
${ }^{10} \mathrm{O}$ termo "inatividade" é utilizado tendo como base o caso clássico em que um indivíduo trabalha durante certo número de anos e ao se aposentar, deixa de trabalhar. No Brasil, porém, sabe-se que um contingente não desprezível de indivíduos se aposenta e continua a exercer algum trabalho. A expressão "inatividade", então, é associada no texto ao recebimento da aposentadoria.
} 


\subsection{Cálculo da alíquota de equilíbrio atuarial}

Um sistema atuarialmente equilibrado requer que o valor presente do fluxo de contribuições e seus rendimentos seja igual ao valor presente do fluxo de aposentadorias a serem recebidas, ou seja, que $V P C=V P A$. Isso implica igualar (3) e (5), ou seja:

$$
\frac{c W_{1}}{(i-w)}\left(\frac{(1+i)^{T}-(1+w)^{T}}{(1+i)^{T}}\right)=\frac{A}{(1+i)^{T}} \frac{1}{i}\left(\frac{(1+i)^{N}-1}{(1+i)^{N}}\right)
$$

que, empregando a expressão de $A$, dada por (6), pode ser reescrita como:

$$
\frac{c}{(i-w)}\left((1+i)^{T}-(1+w)^{T}\right)=\frac{f(1+w)^{0,2 T}}{0,8 w T} \frac{1}{i}\left((1+w)^{0,8 T}-1\right)\left(\frac{(1+i)^{N}-1}{(1+i)^{N}}\right)
$$

Colocando a alíquota de contribuição c em evidência em (7), chega-se à expressão da alíquota contributiva "justa" que gera uma situação de equilíbrio atuarial no sistema ${ }^{11}$ :

$$
c=\frac{f(1+w)^{0,2 T}}{0,8 w T} \frac{1}{i}\left((1+w)^{0,8 T}-1\right)\left(\frac{(1+i)^{N}-1}{(1+i)^{N}}\right) \frac{(i-w)}{(1+i)^{T}-(1+w)^{T}}
$$

se $i \neq w$.

À equação 8a se aplica a mesma ressalva feita à equação 3 . Ou seja, se $w \rightarrow i$ há uma indeterminação. Para poder solucionar o problema, é necessário inicialmente reordenar a equação, para separar os termos no colchete, que independem de $w$ :

$$
\begin{gathered}
c=\left[\left(\frac{(1+i)^{N}-1}{(1+i)^{N}}\right) \frac{f}{0,8 T i}\right] \frac{(1+w)^{0,2 T}\left((1+w)^{0,8 T}-1\right)}{w} \frac{(i-w)}{(1+i)^{T}-(1+w)^{T}} \\
c=\left[\left(\frac{(1+i)^{N}-1}{(1+i)^{N}}\right) \frac{f}{0,8 T i}\right] \frac{f(w)}{g(w)}
\end{gathered}
$$

A seguir, para dar conta da indeterminação, aplica-se a regra de L'Hospital, derivando-se $f(w)$ e $g(w)$ em relação à $w$. Após algumas manipulações, chega-se a:

$$
\begin{aligned}
\frac{f^{\prime}(w)}{g^{\prime}(w)} & =\frac{(1+w)^{0,2 T}\left(0,2 T(1+w)^{-1}\left((1+w)^{0,8 T}-1\right)(i-w)\right)}{(1+i)^{T}-(1+w)^{T}-w T(1+w)^{T-1}} \\
& +\frac{(1+w)^{0,2 T}\left(0,8 T(1+w)^{0,8 T-1}(i-w)+\left(1-(1+w)^{0,8 T}\right)\right)}{(1+i)^{T}-(1+w)^{T}-w T(1+w)^{T-1}}
\end{aligned}
$$

Inserindo-se a expressão acima na equação $8 \mathrm{a}$ e fazendo $w \rightarrow i$, obtém-se (8b). Esta expressão é utilizada nos cálculos das seções posteriores quando ocorre a condição particular $i=w$.

$$
c=\left[\left(\frac{(1+i)^{N}-1}{(1+i)^{N}}\right) \frac{f}{0,8 T i}\right] \frac{(1+i)^{T}-(1+i)^{0,2 T}}{i T(1+i)^{T-1}}
$$

se $i=w$.

\footnotetext{
${ }^{11} \mathrm{~A}$ formulação aqui apresentada, em tempo discreto, é similar àquela desenvolvida em tempo contínuo por Iyer (2002, seção 1.6).
} 


\section{PARTE EMPÍRICA}

Nesta seção é descrito o procedimento econométrico adotado para a estimação de alguns parâmetros utilizados no modelo descrito na seção 3. A seguir são calculadas as alíquotas de equilíbrio atuarial. Com base nesses cálculos, são feitos dois breves exercícios adicionais sobre alíquotas e períodos de acumulação de recursos. Finalizando esta seção, no item 4.3 são feitas algumas considerações de cunho teórico sobre alguns dos resultados obtidos.

\subsection{Procedimento econométrico}

As equações $8 \mathrm{a}$ e $8 \mathrm{~b}$ permitem chegar ao cálculo da alíquota atuarialmente equilibrada, que iguala os valores presentes esperados das contribuições e dos benefícios. Uma variável fundamental nesse tipo de modelo atuarial é $w$, a taxa de crescimento da renda. Por esse motivo, seu valor foi estimado empiricamente por meio de uma regressão log-linear da renda por MQO. Foram empregados os microdados da Pesquisa Nacional por Amostra de Domicílios (PNAD) do ano 2007, realizada pelo IBGE. Na PNAD, conforme ressaltado por Silva, Pessoa e Lila (2002, seções 1 e 2) é empregado um plano amostral estratificado com um, dois ou três estágios de seleção, de acordo com o estrato. Devido a este desenho amostral, os dados da PNAD não podem ser analisados como se fossem observações geradas por amostragem aleatória simples, sem reposição. Tendo em vista essa relevante característica, as estimações feitas levam em conta o plano amostral complexo da PNAD, de acordo com os estratos e unidades primárias de amostragem. Maiores detalhes sobre a operacionalização desse procedimento podem ser vistas também em Osorio (2002).

De forma consistente com o modelo apresentado na seção 3 e com os objetivos do trabalho, na regressão estão incluídos apenas os indivíduos que trabalham no setor privado e que declararam contribuir para a previdência social. Também foram excluídas as pessoas que trabalham na área rural, dado que estas dificilmente poderiam se aposentar nas condições aqui supostas. Estão incluídas na amostra todas as pessoas ocupadas, com renda da ocupação principal positiva, com idades compreendidas entre os 20 e 60 anos, inclusive. ${ }^{12}$ Foram estimadas 4 regressões, cujos resultados são apresentados na Tabela 1, com a mesma forma funcional e amostras diferentes. Na primeira, toda a amostra é utilizada; na regressão 2 estão incluídas apenas as pessoas que possuem até 8 anos de estudo; a regressão 3 abarca os indivíduos que estudaram de 9 a 11 anos; por último, a regressão 4 tem como amostra apenas as pessoas com 12 ou mais anos de estudo.

As variáveis explicativas quantitativas são $\exp$, que representa o número de anos da pessoa no mercado de trabalho (dado pela diferença entre sua idade em 2007 e a idade de entrada no mercado de trabalho), educa, que é o número de anos de estudo completos e a idade com que a pessoa começou a trabalhar, inictrab. A seguir há uma série de variáveis dummy. A primeira é branco, que tem valor 1 se o indivíduo se declara branco ou amarelo e zero em caso contrário. A variável chefe mostra se o indivíduo é chefe de família. A variável metrop assume valor 1 se a pessoa mora em uma região metropolitana. As posições na ocupação são dadas pelas variáveis posocupi. Posocup 1 tem valor 1 para os trabalhadores com carteira de trabalho e zero para os demais. Analogamente posocup 2 refere-se aos trabalhadores sem carteira ou que não declararam se possuem carteira; posocup 3 está relacionada aos empregados domésticos, posocup 4 refere-se aos trabalhadores por conta própria e, finalmente, posocup5 aos empregadores, sendo esta última dummy omitida na regressão). De forma similar, as dummies geográficas representam respectivamente as regiões Norte, Nordeste (omitida), Sudeste, Sul e Centro-Oeste.

As duas últimas variáveis explicativas são formadas por interações. Inictrabeduca é uma interação de inictrab com educa. A variável exphomem é formada pela interação das dummies de experiência

\footnotetext{
${ }^{12}$ Há pessoas que apesar de receberem benefícios previdenciários, ainda estão no mercado de trabalho. Nesse caso, o indivíduo é considerado um trabalhador normal.
} 
(exp) e gênero (homem). Esta última permite que sejam obtidas taxas distintas de crescimento da renda para homens e mulheres. Por exemplo, para a amostra completa, a renda das mulheres cresce, de acordo com a estimação, a uma taxa anual $w$ de 1,29\% (coeficiente da variável exp). Já a taxa de crescimento $w$ da renda masculina é dada pela soma dos coeficientes das variáveis exp exphomem $(0,0129199+0,0067335)$, o que gera uma taxa de $1,97 \%$ a.a. O mesmo raciocínio se aplica às demais regressões apresentadas. Como todos os coeficientes são significativos a $1 \%$, há evidências de que as taxas de crescimento da renda para homens e mulheres são diferentes. Os coeficientes da variável $\exp$, além de significativos, são crescentes com a faixa de renda. Uma possível explicação para este fato é que, ao longo de sua carreira, pessoas com maior nível educacional têm maior probabilidade de acesso a cargos de chefia ou de perfil gerencial, que são associados a rendimentos mais elevados. Os resultados das estimações são reportados na Tabela 1.

Antes de dar continuidade à análise dos dados é necessário comentar algumas das hipóteses adotadas e sua possível influência sobre os resultados deste trabalho. O primeiro ponto é quanto ao cômputo do tempo no mercado de trabalho pela diferença entre a idade em 2007 e a idade em que a pessoa começou a trabalhar. Desta forma, implicitamente está sendo feita uma hipótese que a densidade de contribuições é igual a 100\% (não há períodos em que a pessoa deixa de contribuir) e que não há períodos de desemprego durante a vida ativa. Conjuntamente, essas suposições estão no sentido de aumentar o volume de contribuições ao longo da vida ativa. Adicionalmente, não havendo desemprego, é de se esperar que o trabalhador consiga se aposentar exatamente nas condições mínimas definidas pela legislação. O segundo ponto é quanto à renda do trabalhador. Foi empregada em nossos cálculos apenas a renda da ocupação principal e, consequentemente, a situação como contribuinte à previdência nesse trabalho principal. Com isso, deixa-se de se levar em consideração o fato de que um contingente de trabalhadores tem mais de uma ocupação e pode, também, contribuir ao sistema previdenciário nessas ocupações. No entanto, tal grupo de trabalhadores é bastante reduzido. Da amostra utilizada na regressão 1 da Tabela 1, 64.637 pessoas, apenas 409 (0,63\%) têm duas ocupações e são contribuintes do INSS nessa segunda ocupação. E, apenas $83(0,13 \%)$ contribuem ao INSS pela terceira ocupação. Desta forma, o erro cometido no cálculo do montante de contribuições é de reduzida magnitude.

Cabe ainda uma consideração quanto à forma funcional adotada nos modelos estimados. Em geral modelos de estimação de renda por meio de equações de Mincer incluem um termo quadrático entre as variáveis explicativas. De fato, uma análise visual das figuras 1 a 4 permite inferir que há uma certa concavidade dos rendimentos ao longo do tempo. Este fato poderia ser uma justificativa para que além do termo referente à experiência no mercado de trabalho $(e x p)$ também fosse incluído um termo quadrático $\left(e x p^{2}=e x p * e x p\right)$. No entanto o termo quadrático não foi incluído nas estimações por dois motivos. O primeiro refere-se à consistência do modelo desenvolvido na seção $3 \mathrm{com}$ o procedimento econométrico da seção 4. O modelo baseia-se em uma taxa de crescimento da renda $w$ constante. 0 modelo permite uma solução analítica para a alíquota de contribuição, dada pelas equações 8 a (caso geral) e $8 \mathrm{~b}$ (caso específico, que $i \rightarrow w$. O mesmo se aplica para as extensões desenvolvidas na seção 4. A inclusão do termo quadrático traria complicações analíticas (particularmente para a dedução das expressões dadas nas equações $8 \mathrm{a}$ e $8 \mathrm{~b}$ ) que superariam em muito o ganho obtido no poder explicativo do modelo. 0 segundo motivo é o poder explicativo da variável $e x p^{2}$, que se mostrou bastante reduzido. De forma análoga, o aumento em $R^{2}$ foi virtualmente desprezível ${ }^{13}$ Logo, os rendimentos dos indivíduos podem ser representados por uma equação linear, conforme adotado, com coeficiente de crescimento $w$ constante, com perda quase desprezível na aderência do modelo aos dados verificados empiricamente.

Com base nos coeficientes estimados, a Tabela 2 apresenta as taxas de crescimento da renda $w$ para homens e mulheres, desagregadas por anos de estudo. Posteriormente, as figuras 1 a 4 apresentam a renda média por idade para cada gênero, para a amostra completa e para cada um dos três níveis

\footnotetext{
${ }^{13}$ Os coeficientes do termo $\exp ^{2}$ foram inferiores a 0,0006 em todas as regressões. O valor de $R^{2}$ aumentou apenas 0,01 na $1 .^{a}$ e na $4^{a}$ regressões. Nas demais, o incremento foi ainda menor. Por questão de espaço, os resultados das estimações incluindo o termo quadrático não são apresentados.
} 
Table 1: Regressões lineares por MQO - Variável dependente: ln (renda)

\begin{tabular}{|c|c|c|c|c|}
\hline & Regressão 1 & Regressão 2 & Regressão 3 & Regressão 4 \\
\hline & $\begin{array}{l}\text { Amostra } \\
\text { completa }\end{array}$ & $\begin{array}{l}0 \text { a } 8 \text { anos } \\
\text { de estudo }\end{array}$ & $\begin{array}{l}9 \text { a } 11 \text { anos } \\
\text { de estudo }\end{array}$ & $\begin{array}{l}12 \text { ou mais anos } \\
\text { de estudo }\end{array}$ \\
\hline $\exp$ & $\begin{array}{l}0,01292 \\
(32,86)^{-*}\end{array}$ & $\begin{array}{l}0,00154 \\
(3,11)^{-*}\end{array}$ & $\begin{array}{l}0,01017 \\
(18,90)^{-*}\end{array}$ & $\begin{array}{l}0,01918 \\
(19,40)^{-*}\end{array}$ \\
\hline educa & $\begin{array}{l}0,037 \\
(13,28)^{* *}\end{array}$ & $\begin{array}{l}0,043 \\
(9,35)^{* *}\end{array}$ & $\begin{array}{l}0,072 \\
(3,42)^{-\infty}\end{array}$ & $\begin{array}{l}0,031 \\
-1,15\end{array}$ \\
\hline inictrab & $\begin{array}{l}-0,009 \\
(5,40)^{* *}\end{array}$ & $\begin{array}{l}0,009 \\
(4,97)^{+*}\end{array}$ & $\begin{array}{l}-0,006 \\
-0,41\end{array}$ & $\begin{array}{l}-0,095 \\
(4,30)^{*-*}\end{array}$ \\
\hline branco & $\begin{array}{l}0,153 \\
(26,69)^{* *}\end{array}$ & $\begin{array}{l}0,095 \\
(13,53)^{* *}\end{array}$ & $\begin{array}{l}0,125 \\
(16,42)^{* * *}\end{array}$ & $\begin{array}{l}0,197 \\
(12,16)^{* *}\end{array}$ \\
\hline homem & $\begin{array}{l}0,22 \\
(25,08)^{* *}\end{array}$ & $\begin{array}{l}0,174 \\
(12,82)^{* *}\end{array}$ & $\begin{array}{l}0,147 \\
(12,85)^{* *}\end{array}$ & $\begin{array}{l}0,251 \\
(10,60)^{* *}\end{array}$ \\
\hline chefe & $\begin{array}{l}0,083 \\
(7,92)^{* *}\end{array}$ & $\begin{array}{l}0,051 \\
(3,39)^{* *}\end{array}$ & $\begin{array}{l}0,049 \\
(4,03)^{-*}\end{array}$ & $\begin{array}{l}0,165 \\
(4,85)^{* *}\end{array}$ \\
\hline metrop & $\begin{array}{l}0,107 \\
(13,91)^{* *}\end{array}$ & $\begin{array}{l}0,036 \\
(4,61)^{m}\end{array}$ & $\begin{array}{l}0,087 \\
(10,33)^{* *}\end{array}$ & $\begin{array}{l}0,259 \\
(14,20)^{* *}\end{array}$ \\
\hline posocup 1 & $\begin{array}{l}-0,753 \\
(41,85)^{* * *}\end{array}$ & $\begin{array}{l}-0,865 \\
(25,01)^{* * *}\end{array}$ & $\begin{array}{l}-0,852 \\
(32,59)^{* * *}\end{array}$ & $\begin{array}{l}-0,452 \\
(16,15)^{* *}\end{array}$ \\
\hline posocup2 & $\begin{array}{l}-0,784 \\
(36,44)^{* \ldots *}\end{array}$ & $\begin{array}{l}-0,929 \\
(23,12)^{-\ldots}\end{array}$ & $\begin{array}{l}-0,857 \\
(26,67)^{* *}\end{array}$ & $\begin{array}{l}-0,589 \\
(16,80)^{* *}\end{array}$ \\
\hline posocup3 & $\begin{array}{l}-0,852 \\
(40,76)^{* *}\end{array}$ & $\begin{array}{l}-0,951 \\
(26,10)^{* * *}\end{array}$ & $\begin{array}{l}-1,071 \\
(35,52)^{* *}\end{array}$ & $\begin{array}{l}-1,142 \\
(10,32)^{* *}\end{array}$ \\
\hline posocup4 & $\begin{array}{l}-0,517 \\
(23,88)^{-*}\end{array}$ & $\begin{array}{l}-0,632 \\
(15,85)^{-*}\end{array}$ & $\begin{array}{l}-0,577 \\
(17,28)^{* *}\end{array}$ & $\begin{array}{l}-0,328 \\
(9,10)^{* *}\end{array}$ \\
\hline regiao1 & $\begin{array}{l}0,17 \\
(12,32)^{-*}\end{array}$ & $\begin{array}{l}0,137 \\
(9,49)^{-*}\end{array}$ & $\begin{array}{l}0,166 \\
(10,18)^{* *}\end{array}$ & $\begin{array}{l}0,245 \\
(7,65)^{-*}\end{array}$ \\
\hline regiao3 & $\begin{array}{l}0,249 \\
(26,60)^{-*}\end{array}$ & $\begin{array}{l}0,236 \\
(22,15)^{-\infty}\end{array}$ & $\begin{array}{l}0,261 \\
(26,35)^{* *}\end{array}$ & $\begin{array}{l}0,222 \\
(8,63)^{* *}\end{array}$ \\
\hline regiao4 & $\begin{array}{l}0,225 \\
(18,68)^{-*}\end{array}$ & $\begin{array}{l}0,223 \\
(17,70)^{-*}\end{array}$ & $\begin{array}{l}0,253 \\
(19,63)^{-*}\end{array}$ & $\begin{array}{l}0,174 \\
(5,58)^{-*}\end{array}$ \\
\hline regiao5 & $\begin{array}{l}0,264 \\
(19,47)^{-*}\end{array}$ & $\begin{array}{l}0,202 \\
(14,91)^{-*}\end{array}$ & $\begin{array}{l}0,24 \\
(18,18)^{* *}\end{array}$ & $\begin{array}{l}0,333 \\
(9,94)^{*}\end{array}$ \\
\hline inictrabeduca & $\begin{array}{l}0,003 \\
(16,92)^{-*}\end{array}$ & $\begin{array}{l}-0,001 \\
(2,89)^{-*}\end{array}$ & $\begin{array}{c}0,002 \\
-1,35\end{array}$ & $\begin{array}{l}0,009 \\
(5,73)^{-*}\end{array}$ \\
\hline exphomem & $\begin{array}{l}0,007 \\
(16,07)^{-*}\end{array}$ & $\begin{array}{l}0,007 \\
(12,58)^{-1 *}\end{array}$ & $\begin{array}{l}0,009 \\
(13,85)^{* * *}\end{array}$ & $\begin{array}{l}0,009 \\
(7,22)^{-*}\end{array}$ \\
\hline Constante & $\begin{array}{l}5,82298 \\
(152,24)^{* *}\end{array}$ & $\begin{array}{l}6,40449 \\
(129,93)^{* *}\end{array}$ & $\begin{array}{l}5,71711 \\
(25,07)^{* *}\end{array}$ & $\begin{array}{l}5,54126 \\
(14,31)^{* *}\end{array}$ \\
\hline $\mathrm{N}^{0}$ de obs. & 64.637 & 23.785 & 27.666 & 13.186 \\
\hline$R^{2}$ & 0,45 & 0,33 & 0,37 & 0,39 \\
\hline
\end{tabular}

Estatística $t$ entre parênteses

${ }^{*}$ coeficiente significativo a $5 \%$

*** coeficiente significativo a $1 \%$ 
Table 2: Taxas de crescimento da renda (\% a.a.)

\begin{tabular}{|lll|}
\hline Anos de estudo & Mulheres & Homens \\
\hline Amostra completa & 1,29 & 1,97 \\
0 a 8 & 0,15 & 0,89 \\
9 a 11 & 1,07 & 2,02 \\
12 ou mais & 1,92 & 2,81 \\
\hline
\end{tabular}

Fonte: Elaboração dos autores

educacionais. São claras as diferenças de remuneração (e de sua taxa de crescimento) entre homens e mulheres e também entre os níveis de educação. As maiores variações encontradas nas idades mais avançadas devem ser atribuídas à menor quantidade de indivíduos representados, devido ao grande volume de aposentadorias concedidas a partir do meio da quinta década de vida.

Figure 1: Renda média mensal - homens e mulheres - amostra completa - (Valores em R\$ de setembro de 2007)

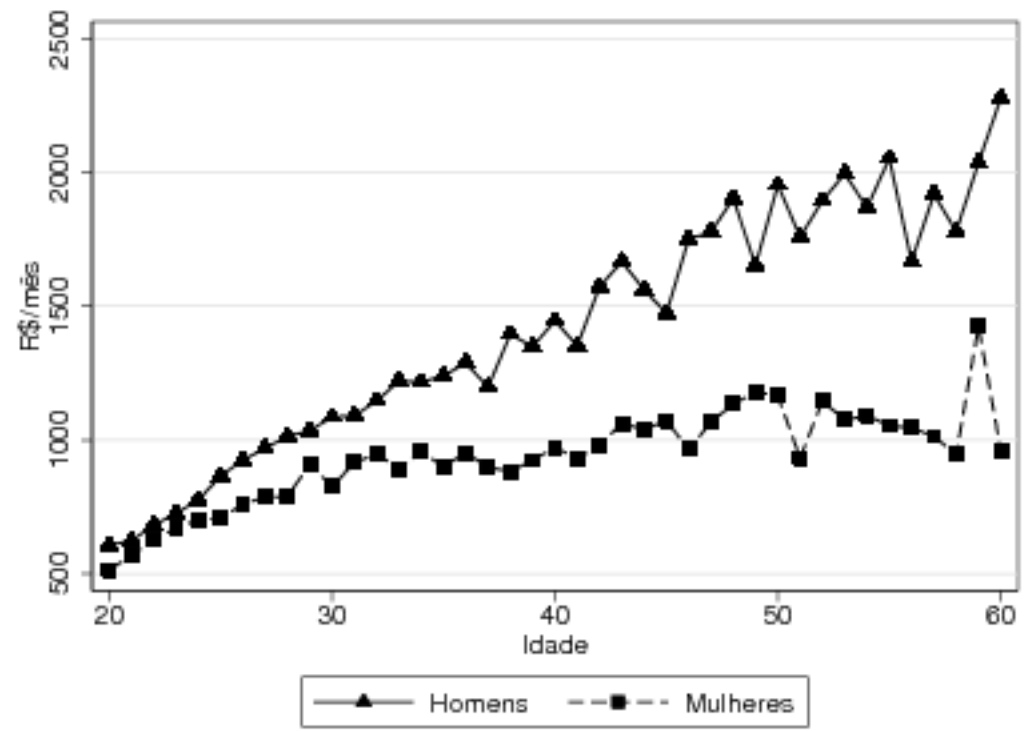

\subsection{Resultados das alíquotas de contribuição atuarialmente justas}

Com base nas equações $8 \mathrm{a}$ e $8 \mathrm{~b}$ e nos parâmetros estimados nas regressões lineares, foram calculadas as alíquotas atuarialmente equilibradas para homens e mulheres, para toda a amostra e também por grupo educacional. No Brasil, a regra de aposentadoria estabelecida na Constituição para os contribuintes do INSS é que o indivíduo pode se aposentar por idade: aos 60 anos as mulheres e aos 65 os homens; ou por tempo de contribuição, com 30 anos de contribuição para as mulheres e 35 anos para os homens. Serão apresentadas as alíquotas referentes às mulheres e aos homens, para a amostra 
Figure 2: Renda média mensal - homens e mulheres - 0 a 8 anos de estudo - (Valores em R $\$$ de setembro de 2007)

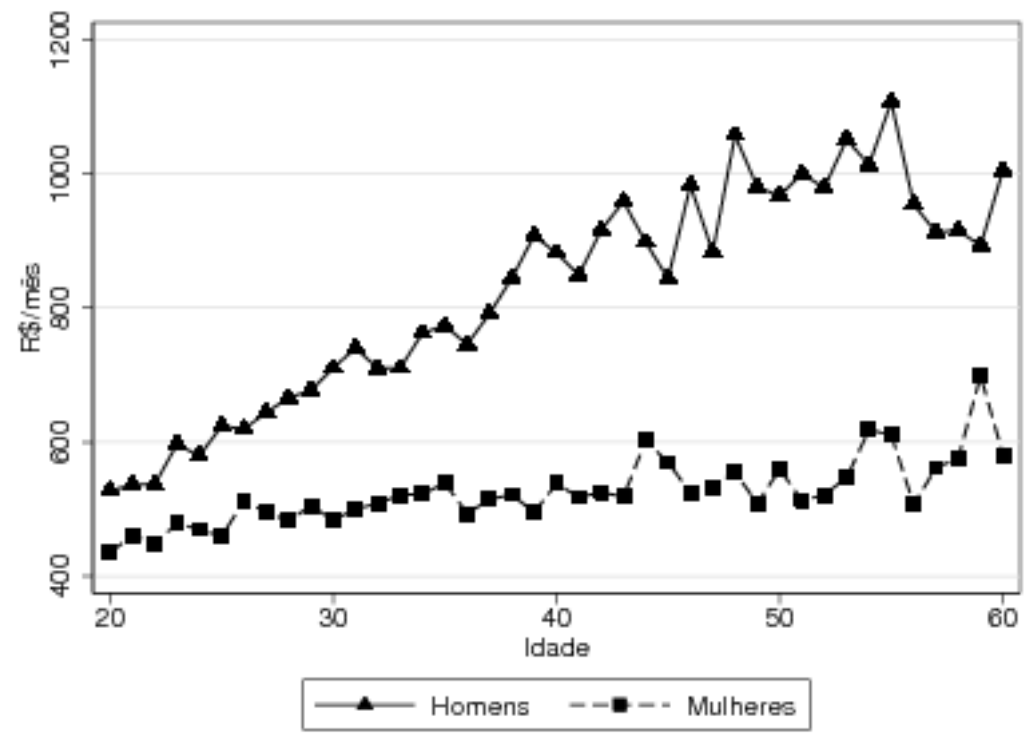

Figure 3: Renda média mensal - homens e mulheres - 9 a 11 anos de estudo - (Valores em R\$ de setembro de 2007)

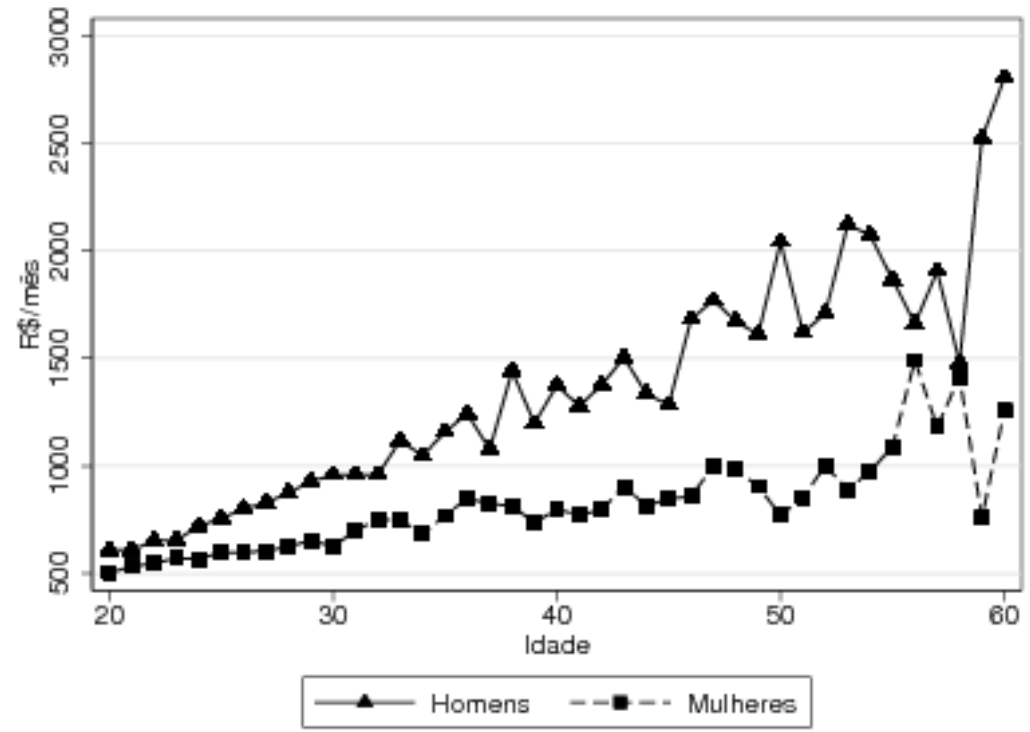


Figure 4: Renda média mensal - homens e mulheres - 12 anos de estudo ou mais - (Valores em R\$ de setembro de 2007)

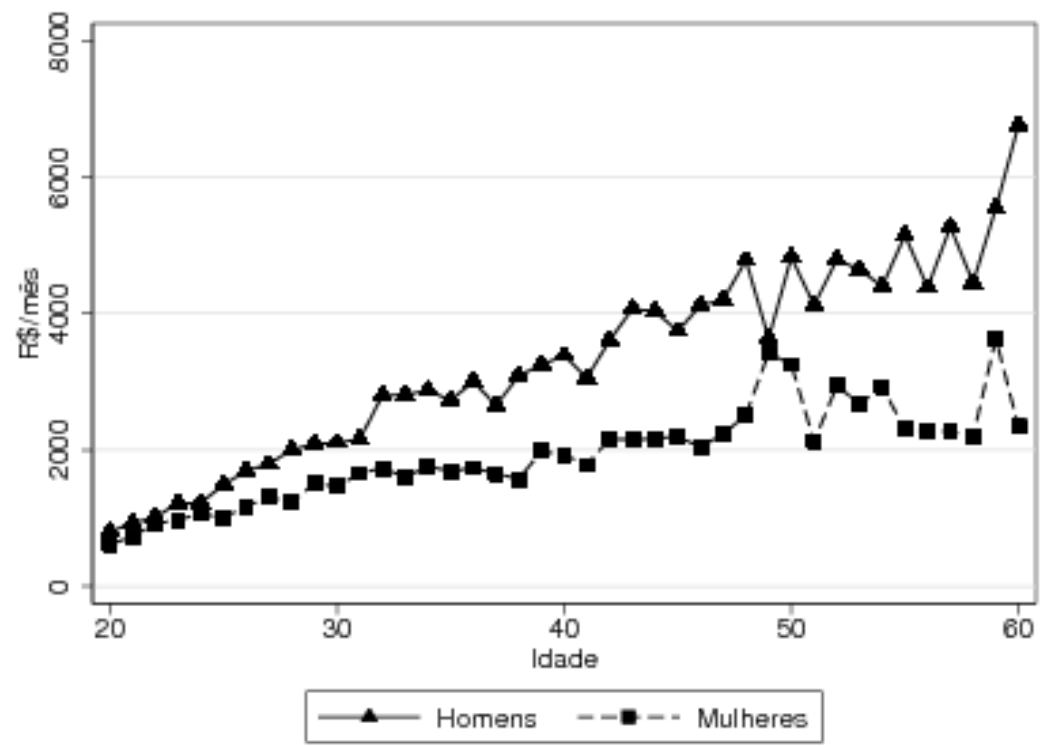

completa e para três níveis de estudo. Para cada gênero, são analisadas duas possibilidades. Para as mulheres, na primeira possibilidade, a aposentadoria ocorre após 30 anos de contribuição. Nesse caso o fator previdenciário tem valor 0,61. Na segunda possibilidade, a aposentadoria é obtida após 35 anos de contribuição e o fator vale 0,84 . Para os homens, analisam-se as hipóteses em que a aposentadoria é conseguida após 35 anos de contribuição (fator igual a 0,73 ) e após 40 anos (fator igual a 1,01). Adota-se como hipótese que o indivíduo começa a trabalhar (e a contribuir) aos 20 anos de idade e falece aos 80 anos. A soma dos períodos de atividade e inatividade é, portanto, a mesma em todas as situações - 60 anos. Todos os resultados são apresentados empregando-se taxas de desconto de 3\% e 4\%. Estas taxas são inferiores àquelas praticadas nos últimos 10 anos no país, No entanto são consistentes com exercícios similares feitos em outros países, em que as taxas de juros utilizadas nos exercícios atuariais costumam se situar entre $2 \%$ e $4 \%{ }^{14}$

Os parâmetros refletem aproximadamente o que acontece com a classe média no Brasil, que é quem tipicamente se aposenta por tempo de contribuição. Comparativamente às classes de menor renda, posterga o ingresso no mercado de trabalho para continuar os estudos até o nível superior e tem uma expectativa de vida, no momento da aposentadoria, próxima aos 80 anos. ${ }^{15}$ Seguindo as regras do INSS, supõe-se que o valor da aposentadoria é dado pelo fator previdenciário multiplicado pela média dos maiores $80 \%$ salários de contribuição e que, após o recebimento do primeiro benefício, este preserva

\footnotetext{
${ }^{14} \mathrm{~A}$ escolha dessas taxas tem como base o rendimento líquido real de um título público. No momento em que esse texto era finalizado, a expectativa era que a taxa Selic no final de 2009 seja da ordem de $11 \%$ a.a. Considerando uma alíquota de imposto de renda de $20 \%$ para uma aplicação de 1 ano e uma taxa de inflação de cerca de $4,5 \%$ a.a, chega-se a valores reais próximos às taxas de desconto aqui adotadas.

${ }^{15} \mathrm{Na}$ média de ambos os sexos, a expectativa de vida aos 50 anos de idade no Brasil é de 78,8 anos (sobrevida de 28,8 anos); aos 55, de 79,8 anos; e aos 60, de 81,1 anos. Essas são as idades de aposentadoria após 30, 35 e 40 anos de trabalho, respectivamente, para quem começa a trabalhar aos 20 anos.
} 
o seu valor e não sofre variações em termos reais. ${ }^{16}$ Finalmente, o fator previdenciário $f$ de (8a) e (8b) foi obtido da Tabela A-2 (ver Apêndice), que corresponde ao fator efetivamente vigente no Brasil em função da legislação aprovada no segundo Governo Cardoso no momento em que esse artigo está sendo concluído (2009). Cabe lembrar que, no caso das mulheres, o tempo de contribuição empregado no cálculo do fator previdenciário incorpora o bônus de 5 anos a que elas têm direito, conforme definido pela legislação. ${ }^{17} \mathrm{O}$ fator previdenciário de uma mulher que contribui para o INSS por 30 anos e se aposenta com 50 anos de idade - porém, como se fossem 35 anos de contribuição para efeitos do fator - é de 0,61 na Tabela A-2, o que significa que a mulher se aposenta com uma remuneração igual a $61 \%$ da média de salários de contribuição considerada - no caso, os $80 \%$ maiores salários do período de 30 anos.

Os resultados são reportados nas Tabelas 3 e 4 . Como forma de avaliar a sensibilidade da alíquota calculada $c$ para diferentes valores da taxa $w$ (e para incorporar os eventuais ganhos de produtividade da economia a cada ano, não captados nas estimações realizadas), em cada tabela também são apresentados nas linhas finais os valores das alíquotas calculadas paras as taxas de crescimento $w$ de $2 \%, 3 \%$, $4 \%$ e $5 \%$.

Table 3: Alíquotas de contribuição atuarialmente equilibradas - mulheres

\begin{tabular}{|lccccc|}
\hline \multicolumn{1}{c}{ Grupo } & $\begin{array}{c}\text { Taxa de crescimento } \\
\text { da renda } w \text { (\% a.a.) }\end{array}$ & $\begin{array}{c}\text { Período contributivo: } \\
\text { 30 anos }\end{array}$ & \multicolumn{2}{c|}{$\begin{array}{c}\text { Período contributivo: } \\
\text { 35 anos }\end{array}$} \\
\cline { 2 - 6 } & & $\begin{array}{r}\text { Fator previdenciário: } 0,61 \\
\text { Taxa de juros } i\end{array}$ & $\begin{array}{c}\text { Fator previdenciário: } 0,84 \\
\text { Taxa de juros } i\end{array}$ \\
\cline { 2 - 6 } & & 3,0 & 4,0 & 3,0 & 4,0 \\
\hline Amostra completa & 1,29 & 26,8 & 20,2 & 26,2 & 19,5 \\
0 a 8 anos de estudo & 0,15 & 25,3 & 19,0 & 24,4 & 18,0 \\
9 a 11 anos de estudo & 1,07 & 26,5 & 20,0 & 25,9 & 19,2 \\
12 anos de estudo & 1,92 & 27,6 & 20,9 & 27,2 & 20,4 \\
ou mais & & & & 27,3 & 20,5 \\
\hline Todos os grupos & 2,00 & 27,7 & 21,0 & 28,8 & 21,9 \\
& 3,00 & 29,0 & 22,1 & 23,2 \\
& 4,00 & 30,2 & 23,2 & 30,3 & 24,5 \\
\hline
\end{tabular}

: Fonte: Elaboração dos autores.

Os dados das Tabelas 3 e 4 mostram que as alíquotas de equilíbrio referentes às mulheres são sempre mais elevadas do que as alíquotas dos homens. Isso se deve ao seu menor período contributivo (e maior período de recebimento da aposentadoria) e, principalmente, à fórmula de cálculo do fator previdenciário que lhes concede o bônus de 5 anos. Por exemplo, para homens com 0 a 8 anos de estudo (cuja taxa anual de crescimento da renda é $w=0,89 \%$ ), adotando-se uma taxa de juros real de 3\%, com período contributivo de 35 anos, é necessária uma alíquota de contribuição de $22,2 \%$. Isso significa que se o sistema fosse de capitalização, uma alíquota como essa, incidente sobre a renda de um indivíduo, permitiria que este ao final dos 35 anos de trabalho (e contribuição), tendo começado a trabalhar aos 20 anos de idade, acumulasse um determinado capital. Este capital, continuando a render 3\% todos os anos, permitiria uma descapitalização nos 25 anos seguintes (dos 55 aos 80 anos), de tal forma que

\footnotetext{
${ }^{16}$ Note-se que os cálculos aqui apresentados aplicam-se para situações em que o valor da aposentadoria calculada está compreendido entre os limites mínimo e máximo do benefício do INSS.

${ }^{17}$ Isso significa que o tempo de 30 anos, por exemplo, é computado como sendo de 35 anos de contribuição para calcular o valor do fator previdenciário.
} 
Table 4: Alíquotas de contribuição atuarialmente equilibradas - homens

\begin{tabular}{|lccccc|}
\hline \multicolumn{1}{c}{ Grupo } & $\begin{array}{c}\text { Taxa de crescimento } \\
\text { da renda } w \text { (\% a.a.) }\end{array}$ & $\begin{array}{c}\text { Período contributivo: } \\
\text { 35 anos }\end{array}$ & \multicolumn{2}{c|}{$\begin{array}{c}\text { Período contributivo: } \\
\end{array}$} \\
\cline { 2 - 6 } & & $\begin{array}{r}\text { Fator previdenciário: } 0,73 \\
\text { Taxa de juros } i\end{array}$ & $\begin{array}{c}\text { Fator previdenciário: } 1,01 \\
\text { Taxa de juros } i\end{array}$ \\
\cline { 2 - 6 } & & 3,0 & 4,0 & 3,0 & 4,0 \\
\hline Amostra completa & 1,97 & 23,7 & 17,8 & 23,0 & 17,1 \\
0 a 8 anos de estudo & 0,89 & 22,2 & 16,5 & 21,3 & 15,6 \\
9 a 11 anos de estudo & 2,02 & 23,8 & 17,8 & 23,1 & 17,2 \\
12 anos de estudo & 2,81 & 24,8 & 18,8 & 24,3 & 18,3 \\
ou mais & & & & 23,1 & 17,1 \\
\hline Todos os grupos & 2,00 & 23,7 & 17,8 & 24,7 & 18,5 \\
& 3,00 & 25,1 & 19,0 & 26,2 & 19,9 \\
& 4,00 & 26,4 & 20,2 & 27,7 & 21,3 \\
\hline
\end{tabular}

: Fonte: Elaboração dos autores.

seria suficiente para custear a aposentadoria do trabalhador. Para uma mulher em condições análogas, a alíquota seria $25,3 \%$. As diferenças mais expressivas, em cada gênero, encontram-se nas diferentes colunas, de acordo com as taxas de juros utilizadas. As alíquotas calculadas são consistentemente mais elevadas para os grupos de nível educacional mais elevado, embora as diferenças não sejam tão grandes em relação aos demais grupos.

Note-se também que para períodos contributivos mais longos, como já era de se esperar, as alíquotas de contribuição são mais baixas, mas a diferença não é tão expressiva quanto se poderia supor a princípio. O motivo é que há dois efeitos atuando em sentidos opostos. De um lado, um período contributivo maior e um período de recebimento de benefícios menor implicam em uma alíquota de equilíbrio mais baixa. Por outro lado, este prolongamento do período contributivo faz com que a pessoa se aposente com uma idade mais elevada e, portanto, tenha um fator previdenciário mais alto, o que eleva o valor de sua aposentadoria. Como o primeiro efeito tem uma magnitude um pouco maior, o resultado é uma redução suave na alíquota de equilíbrio.

Como pode ser notado na tabelas 3 e 4 em todos as situações analisadas (com exceção dos homens que se aposentam após 40 anos de contribuição), o fator previdenciário é inferior a um. Isto faz com que o benefício seja inferior à média das $80 \%$ melhores rendas do período laboral. Adicionalmente deve-se lembrar que nos cálculos efetuados supôs-se que as pessoas aposentam-se tão logo completem o período contributivo mínimo. Destes fatos surge uma questão: quão sensíveis são os resultados encontrados para as alíquotas de contribuição necessárias se os trabalhadores resolverem postergar sua aposentadoria por mais alguns anos? Essa questão pode ser interpretada também de outra forma: quais os impactos de uma elevação no período contributivo mínimo exigido legalmente, de forma que para ambos os gêneros, o fator previdenciário seja superior à unidade ${ }^{18}$ Para responder a essa indagação, calculam-se as alíquotas atuarialmente justas para homens e mulheres considerando-se um incremento de 5 anos no tempo de contribuição mínimo. Assim, os resultados reportados nas Tabelas 5 e 6 referemse, respectivamente, à situação em que a mulheres após 40 anos de contribuição (fator igual a 1,15) e os homens se aposentam tendo contribuído por 45 anos (fator igual a 1,42).

\footnotetext{
${ }^{18} \mathrm{Na}$ prática esta alteração corresponde a uma idade mínima de aposentadoria de 65 anos para os homens e 60 anos para as mulheres, valores mais próximos daqueles adotados na maioria dos países.
} 
Table 5: Alíquotas de contribuição atuarialmente equilibradas (Período estendido) - mulheres

\begin{tabular}{|lccc|}
\hline \multicolumn{1}{|c}{ Grupo } & $\begin{array}{c}\text { Taxa de crescimento } \\
\text { da renda } w \text { (\% a.a.) }\end{array}$ & \multicolumn{2}{c|}{$\begin{array}{c}\text { Período contributivo: } \\
\text { 40 anos }\end{array}$} \\
\cline { 2 - 4 } & & $\begin{array}{r}\text { Fator previdenciário: } 1,15 \\
\text { Taxa de juros } i\end{array}$ \\
\cline { 2 - 4 } & & 3,0 & 4,0 \\
\hline Amostra completa & 1,29 & 25,0 & 18,4 \\
0 a 8 anos de estudo & 0,15 & 23,0 & 16,7 \\
9 a 11 anos de estudo & 1,07 & 24,6 & 18,1 \\
12 anos de estudo & 1,92 & 26,1 & 19,4 \\
ou mais & & & \\
\hline Todos os grupos & 2,00 & 26,3 & 19,5 \\
& 3,00 & 28,1 & 21,1 \\
& 4,00 & 29,8 & 22,7 \\
& 5,00 & 31,5 & 24,3 \\
\hline
\end{tabular}

: Fonte: Elaboração dos autores.

Table 6: Alíquotas de contribuição atuarialmente equilibradas (Período estendido) - homens

\begin{tabular}{|lccc|}
\hline \multicolumn{1}{|c}{ Grupo } & $\begin{array}{c}\text { Taxa de crescimento } \\
\text { da renda } w \text { (\% a.a.) }\end{array}$ & \multicolumn{2}{c|}{$\begin{array}{c}\text { Período contributivo: } \\
\text { 45 anos }\end{array}$} \\
\cline { 2 - 4 } & & $\begin{array}{r}\text { Fator previdenciário: } 1,42 \\
\text { Taxa de juros } i\end{array}$ \\
\cline { 2 - 4 } & & 3,0 & 4,0 \\
\hline Amostra completa & 1,97 & 21,7 & 16,0 \\
0 a 8 anos de estudo & 0,89 & 19,8 & 14,3 \\
9 a 11 anos de estudo & 2,02 & 21,8 & 16,0 \\
12 anos de estudo & 2,81 & 23,2 & 17,3 \\
ou mais & & & \\
\hline Todos os grupos & 2,00 & 21,8 & 16,0 \\
& 3,00 & 23,5 & 17,6 \\
& 4,00 & 25,3 & 19,2 \\
& 5,00 & 26,9 & 20,7 \\
\hline
\end{tabular}

: Fonte: Elaboração dos autores. 
Como já era de se esperar, as alíquotas calculadas são mais baixas, comparativamente aos casos correspondentes apresentados nas Tabelas 3 e 4 . É importante notar que as alíquotas não variam de forma linear com os incrementos de 5 anos no período contributivo. Para as mulheres, quando se passa dos 30 para os 35 anos, a redução média na alíquota calculada (com taxa de juros de 3\%) é de $1,25 \% .{ }^{19}$ Quando o incremento é de 35 para 40 anos, alíquota cai em média 3,51\%. Para os homens os valores análogos são 2,06\% e 4,96\%. Neste segundo caso, esta redução mais significativa está associada principalmente à variação do fator previdenciário, maior para os homens do que para as mulheres. Outro ponto a ser ressaltado é que quanto menor a taxa de crescimento da renda, maior a magnitude da redução da alíquota de contribuição calculada.

\subsection{Três extensões}

A metodologia de cálculo descrita na seção anterior permite que sejam feitas três extensões do modelo adotado. A primeira corresponde ao cálculo da taxa de reposição previdenciária, que é dada pela relação entre os valores da primeira aposentadoria e da remuneração no último período laboral, conforme apresentado na equação 8:

$$
T R=\frac{A_{T+1}}{W_{T}}
$$

O valor da aposentadoria utilizado para a obtenção dos resultados das Tabelas 3 e 4 foi calculado (em conformidade com as regras do INSS) por meio da multiplicação do fator previdenciário pelas $80 \%$ maiores contribuições. No modelo em questão, como se supôs uma curva de rendimentos monotonicamente crescente, esse período contributivo corresponde aos $80 \%$ últimos anos da vida laboral do indivíduo. No caso de 35 anos de contribuição, este período é dado pelo intervalo entre o $8^{\circ}$ e o $35^{\circ}$ anos (inclusive) do indivíduo no mercado de trabalho. Assim, não são levados em consideração no cálculo os períodos 1 a 7 , correspondentes aos $20 \%$ menores rendimentos. O exercício aqui efetuado utiliza as alíquotas atuarialmente justas para cada grupo de trabalhadores, apresentadas nas Tabelas 3 a 6. Nos cálculos efetuados supõe-se que as contribuições são capitalizadas a cada período à taxa de juros $i$. Quando o indivíduo se aposenta, os recursos acumulados continuam a ser capitalizados à mesma taxa de juros $i$, mas agora não há mais contribuições e sim o recebimento da aposentadoria, de valor A, até que o montante acumulado se esgote. ${ }^{20}$

Exemplificando: para os homens com 0 a 8 anos de estudo, com uma remuneração inicial de 100 unidades monetárias, a renda quando da aposentadoria seria de 135,06 e a renda média seria de 120,17. Desta maneira, com um fator previdenciário igual a 0,73 , o valor da aposentadoria seria igual a 87,73. De acordo com a equação (9), dividindo-se 87,73 por 135,06 chega-se a uma taxa de reposição de 0,65 . A Tabela A-1, no Apêndice, apresenta os valores empregados neste exemplo.

As Tabelas 7 e 8 apresentam as taxas de reposição TR para todos os grupos formados pelas combinações de gênero, nível educacional e período contributivo apresentados na seção 4.2. Os dados permitem algumas conclusões. Conforme era esperado, quanto maior o período contributivo, mais elevada é a taxa de reposição. Para períodos contributivos iguais, as taxas de reposição das mulheres são mais elevadas que as taxas masculinas. Isso se deve a dois motivos. O primeiro é a fórmula do fator previdenciário, no qual se somam 5 anos ao tempo de contribuição das mulheres. O segundo motivo é que as mulheres têm taxas de crescimento da renda mais baixas que os homens. Taxas de cresci-

\footnotetext{
${ }^{19}$ Este valor foi obtido computando-se a média das variações percentuais dos valores das alíquotas que constam na $5^{a}$ coluna (correspondentes ao fator previdenciário igual a 0,84) da Tabela 3 com relação aos valores que constam na $3^{a}$ coluna (fator igual a 0,61) da mesma tabela. Para os demais valores reportados, os cálculos são análogos.

${ }^{20}$ Note-se que como todos os valores são capitalizados (ou descontados) à mesma taxa de juros i, a escolha desta não afeta a taxa de reposição TR.
} 
mento da renda demandam alíquotas atuarialmente justas mais elevadas. ${ }^{21}$ Também pode ser notado que ceteris paribus, quanto menor o nível educacional (e, consequentemente a renda), mais elevada é a taxa de reposição. Finalmente, também pode ser apontado que, ao contrário do que o senso comum pode usualmente avaliar, para períodos contributivos de 35 para as mulheres e 40 anos para os homens a taxa de reposição é elevada para os padrões internacionais, situando-se próxima a 0,73 para o caso feminino e 0,78 para o caso masculino.

Table 7: Taxas de reposição - mulheres

\begin{tabular}{|lcccc|}
\hline \multicolumn{1}{|c}{ Grupo } & $\begin{array}{c}\text { Taxa de crescimento } \\
\text { da renda } w \text { (\% a.a.) }\end{array}$ & $\begin{array}{c}\text { Período: } \\
\text { contributivo: } \\
30 \text { anos }\end{array}$ & $\begin{array}{c}\text { Período } \\
\text { contributivo: } \\
35 \text { anos }\end{array}$ & $\begin{array}{c}\text { Período } \\
\text { contributivo: } \\
40 \text { anos }\end{array}$ \\
\cline { 2 - 5 } & & Fator: 0,61 & Fator: 0,84 & Fator: 1,15 \\
\hline Amostra completa & 1,29 & 0,53 & 0,71 & 0,95 \\
0 a 8 anos de estudo & 0,15 & 0,60 & 0,82 & 1,12 \\
9 a 11 anos de estudo & 1,07 & 0,54 & 0,73 & 0,98 \\
12 anos de estudo & 1,92 & 0,49 & 0,66 & 0,87 \\
ou mais & & & & \\
\hline Todos os grupos & 2,00 & 0,49 & 0,65 & 0,86 \\
& 3,00 & 0,44 & 0,58 & 0,75 \\
& 4,00 & 0,40 & 0,52 & 0,67 \\
& 5,00 & 0,37 & 0,47 & 0,60 \\
\hline
\end{tabular}

: Fonte: Elaboração dos autores.

Table 8: Taxas de reposição - homens

\begin{tabular}{|c|c|c|c|c|}
\hline Grupo & $\begin{array}{l}\text { Taxa de crescimento } \\
\text { da renda } w \text { (\% a.a.) }\end{array}$ & $\begin{array}{c}\text { Período: } \\
\text { contributivo: } \\
35 \text { anos }\end{array}$ & $\begin{array}{c}\text { Período } \\
\text { contributivo: } \\
40 \text { anos }\end{array}$ & $\begin{array}{c}\text { Período } \\
\text { contributivo: } \\
45 \text { anos }\end{array}$ \\
\hline & & Fator: 0,73 & Fator: 1,01 & Fator: 1,42 \\
\hline Amostra completa & 1,97 & 0,57 & 0,76 & 1,03 \\
\hline 0 a 8 anos de estudo & 0,89 & 0,65 & 0,88 & 1,22 \\
\hline 9 a 11 anos de estudo & 2,02 & 0,56 & 0,75 & 1,02 \\
\hline $\begin{array}{l}12 \text { anos de estudo ou mais } \\
\text { ou mais }\end{array}$ & 2,81 & 0,52 & 0,68 & 0,91 \\
\hline \multirow[t]{4}{*}{ Todos os grupos } & 2,00 & 0,57 & 0,76 & 1,03 \\
\hline & 3,00 & 0,50 & 0,66 & 0,89 \\
\hline & 4,00 & 0,45 & 0,59 & 0,78 \\
\hline & 5,00 & 0,41 & 0,52 & 0,69 \\
\hline
\end{tabular}

: Fonte: Elaboração dos autores.

É feita agora uma segunda extensão. Calcula-se por quantos anos um fundo constituído mediante o procedimento de capitalização acima descrito permitiria lastrear, dada uma alíquota de contribuição como a de fato vigente no Brasil, de $31 \%$, uma aposentadoria por idade para uma mulher. De forma

${ }^{21}$ Sobre este ponto, ver a seção 4.4 . 
distinta do caso anterior, o valor deste benefício é dado somente pela média dos $80 \%$ maiores salários de contribuição ${ }^{22}$. Supõe-se nesses cálculos que a renda cresce a uma taxa de 0,15\% a.a. Essa é a taxa referente à evolução da renda das mulheres com 0 a 8 anos de estudo. Os cálculos são feitos para os períodos contributivos de 15 e 20 anos. Os resultados são apresentados na Tabela 9 a seguir. Como pode ser notado, para uma taxa de juros de $3 \%$ a.a. e um período contributivo de 15 anos, o fundo esgota-se em 7 anos.

Table 9: Número de anos com aposentadorias lastreadas, para diferentes períodos de contribuição ( $c=$ $0,31, w=0,15 \%$ a.a.)

\begin{tabular}{|lcc|}
\hline Anos de contribuição & \multicolumn{2}{c|}{ Taxa de juros real (\%) } \\
\hline \multirow{3}{*}{15} & 3,0 & 4,0 \\
\cline { 2 - 3 } 20 & 7 & 8 \\
& 10 & 12 \\
\hline
\end{tabular}

: Fonte: Elaboração dos autores, com base na mesma metodologia do apêndice.

A Tabela 9 é importante, porque permite aferir o grau de distorção permitida pela figura da aposentadoria por idade, que no Brasil é concedida aos 60 anos para as mulheres e 65 para os homens. Apesar dos incrementos planejados, o requisito contributivo deverá ser de apenas 15 anos e só em 2011, uma vez que em 2009 é ainda de 14 anos, por conta da legislação vigente que estabelece um aumento de 6 meses por anos até o citado teto de 15 anos. Isso significa que, mesmo no final da referida transição, uma pessoa do sexo feminino que se aposente com 60 anos e 15 de contribuição teria, se o sistema fosse de capitalização, lastro para receber aposentadoria apenas durante apenas 7 anos, quando na prática ela tenderá a receber o benefício por 23 anos, já que a expectativa de vida de uma pessoa do sexo feminino que chega viva aos 60 anos é de 83 anos. ${ }^{23}$

Faz-se finalmente a terceira extensão, complementar às duas primeiras. O ponto de partida é a equação 9:

$$
S=S_{-1}(1+i)+c W-A
$$

em que $S$ é o saldo de uma hipotética capitalização, $i$ é a taxa de juros real, $c$ é a alíquota contributiva, $W$ é a renda de contribuição e $A$ é o valor da aposentadoria. A cada período de tempo, $W$ e $A$ são excludentes, implicando que quando há contribuições ainda sendo feitas, o indivíduo não recebe aposentadoria e, a partir do momento em que esta passa a ser recebida, cessam os salários de contribuição. Portanto, dada uma taxa de juros $i$ e a fórmula de cálculo da aposentadoria, supondo perfeita previsibilidade da data de falecimento, há apenas um único valor de $c$ que torna o saldo final igual a zero. O que se faz aqui, portanto, é inverter o raciocínio da Tabela 9, em que se supunha uma dada contribuição e calculava em qual período o saldo acumulado se esgotava. Agora se calcula a alíquota contributiva que preserva o saldo positivo até o último momento, em que ele é zerado.

Na Tabela 10 apresenta-se o valor da alíquota contributiva atuarialmente adequada, adotando-se uma variação salarial anual de $2 \%$ e uma taxa de capitalização $i$ de $3 \%$, supondo que a pessoa viva até os 80 anos de idade. 0 valor da aposentadoria por idade é igual a $70 \%$ do salário de benefício, acrescido

\footnotetext{
${ }^{22} \mathrm{~A}$ legislação faculta a aplicação do fator previdenciário para as aposentadorias por idade.

${ }^{23}$ Deve ser notado que, se por um lado a legislação é leniente acerca de certos benefícios, por outro ela é arbitrária por "punir" aqueles que contribuíram, mas saíram do mercado de trabalho. Por exemplo, uma mulher que tenha trabalhado e contribuído por 12 anos e depois deixado de contribuir por ter tido um filho e se afastado do mercado de trabalho, perderá o vínculo contributivo e não terá direito a qualquer benefício.
} 
de $1 \%$ para cada conjunto de 12 contribuições mensais, até o limite de $100 \%$ do salário de benefício. Por sua vez, o salário de benefício é dado pela média dos $80 \%$ maiores salários de contribuição, corrigidos pelo Índice de Preços ao Consumidor Amplo (IPCA). ${ }^{24}$

Table 10: Alíquotas atuarialmente equilibradas para diferentes idades de início da contribuição $(w=$ $2,00 \%$ a.a.; $i=0,03$ ) /a

\begin{tabular}{|ccc|}
$\begin{array}{c}\text { Idade de início } \\
\text { das contribuições }\end{array}$ & Homens & Mulheres \\
\hline 40 & 33,6 & 52,7 \\
45 & 42,3 & 70,7 \\
50 & 56,7 & - \\
\hline /a Considera-se que a mulher se aposenta por idade aos \\
60 anos de idade e o homem aos 65 anos de idade. Supõe-se \\
que o falecimento da pessoa ocorre aos 80 anos de idade.
\end{tabular}

Na Tabela 10, um homem que começa a contribuir aos 40 anos de idade, por um período de 25 anos, pode se aposentar por idade aos 65 anos. Irá viver, face à hipótese adotada, até os 80 anos. Já uma mulher que comece a trabalhar com a mesma idade, poderá se aposentar aos 60 anos, contribuindo 5 anos a menos e recebendo a aposentadoria por 20 e não por 15 anos, o que significa que, em um sistema de capitalização puro, deveria ter uma alíquota contributiva maior. Note-se que nesse caso, a alíquota contributiva do homem deveria ser de $33,6 \%$ e a da mulher - que contribuiria 20 anos e receberia aposentadoria por outro tanto - de nada menos que $52,7 \%$. No caso de começo de contribuição aos 45 anos, a contribuição seria ainda mais elevada. ${ }^{25}$

Deve ser notado também que, não obstante a importância relativa da aposentadoria da idade no total de aposentadorias, seu valor médio é bastante inferior ao da aposentadoria por tempo de contribuição (ATC). Segundo dados do BEPS, em dezembro de 2008 foram, incluindo-se apenas os benefícios previdenciários, emitidas 14.453 .455 aposentadorias. Deste total, há 7.500 .092 (51,9\%) aposentadorias por idade, $2.835 .391(19,6 \%)$ aposentadorias por invalidez e $4.117 .972(28,5 \%)$ aposentadorias por tempo de contribuição. Os valores médios das aposentadorias por invalidez e por idade eram, respectivamente, de R $\$ 552,01$ e R $\$ 432,97$. Estes dados contrastam com o valor médio das ATC, que era de R\$ $1.058,93$.

\subsection{Um olhar adicional sobre a alíquota de contribuição}

É interessante notar, com base nos resultados da seção 4.2, que para os valores dos parâmetros analisados, a alíquota de contribuição c necessária depende positivamente da taxa de crescimento da renda $w$. Isso pode ser visualizado mais claramente reescrevendo-se 8a e fazendo a derivação em relação a $w$.

$$
\frac{d c}{d w}=\frac{d}{d w}\left(\frac{f(1+w)^{0,2 T}}{0,8 w T} \frac{1}{i}\left((1+w)^{0,8 T}-1\right)\left(\frac{(1+i)^{N}-1}{(1+i)^{N}}\right) \frac{(i-w)}{(1+i)^{T}-(1+w)^{T}}\right)
$$

Rearranjando a equação obtém-se:

\footnotetext{
${ }^{24}$ Ou seja, por exemplo, quem contribui durante 20 anos se aposenta com $90 \%$ da média dos $80 \%$ maiores salários de contribuição.

${ }^{25} \mathrm{Não}$ se considerou o exemplo da mulher que começa a contribuir aos 50 anos, porque ao chegar à idade de aposentadoria, não preencheria o requisito de elegibilidade de 15 anos de contribuição.
} 


$$
\frac{d c}{d w}=\frac{f}{0,8 T i}\left(\frac{(1+i)^{N}-1}{(1+i)^{N}}\right) \frac{d}{d w}\left(\frac{(1+w)^{T}-(1+w)^{0,2 T}}{w} \frac{(i-w)}{(1+i)^{T}-(1+w)^{T}}\right)
$$

E, finalmente, procedendo-se a derivação em relação a $w$, pode-se obter:

$$
\begin{aligned}
& \frac{d c}{d w}= {\left[\frac{f}{0,8 T i}\left(\frac{(1+i)^{N}-1}{(1+i)^{N}}\right)\right]\left[\left(T(1+w)^{T-1}-0,2 T(1+w)^{0,2 T-1}\right)\right.} \\
&(i-w)-\left((1+w)^{T}-(1+w)^{0,2 T}\right)\left(w(1+i)^{T}-(1+w)^{T}\right)-\left((1+w)^{T}-(1+w)^{0,2 T}\right) \\
&\left.\left((1+i)^{T}-(1+w)^{T}-w T(1+w)^{T-1}\right)(i-w)\right] /\left[w\left((1+i)^{T}-(1+w)^{T}\right)\right]^{2}
\end{aligned}
$$

A expressão no primeiro colchete da equação 13 , que independe de $w$, é positiva. O termo no denominador (terceiro colchete) também é positivo. Desta maneira, o sinal da derivada depende do valor da expressão no segundo colchete. Quando $i>w$, é trivial ver que o valor da expressão é positivo. Se $i<w$, os sinais negativos dos termos $(i-w)$ e $\left(w\left((1+i)^{T}-(1+w)^{T}\right)\right)$ se cancelam. Raciocínio análogo se aplica aos termos finais do colchete. A princípio, poderia parecer que uma taxa de crescimento da renda $w$ mais elevada implicaria uma alíquota de contribuição mais baixa. No entanto, como o benefício é calculado com base nos $80 \%$ maiores contribuições, se a renda cresce a uma taxa mais elevada, isso implica um benefício mais elevado, que só pode ser custeado de forma atuarialmente justa com uma alíquota de contribuição mais elevada.

\section{O QUE OS RESULTADOS PERMITEM INFERIR PARA O BRASIL?}

Na Tabela A-2, no Apêndice, mostram-se os valores do fator previdenciário vigentes no início de 2009. Esse fator leva em conta a expectativa de sobrevida e é multiplicado pelo salário médio de contribuição - descartando os 20\% inferiores - após junho de 1994 para chegar ao valor da aposentadoria. Como já foi explicado, as mulheres ganham um bônus de 5 anos na contagem do tempo de contribuição. Uma pessoa do sexo feminino que tenha começado a contribuir aos 20 anos e que contribua sobre um valor fixo constante terá aos 55 anos - com 35 anos de contribuição que contarão como 40 - um fator previdenciário de 0,84 . Se postergar a sua aposentadoria por 3 anos, aos 58, com 38 de contribuição que valerão como 43 , o fator já será superior à unidade $(1,02)$.

Aos 55/60 anos, um indivíduo do sexo masculino tem a expectativa de viver até aproximadamente $78 / 79$ anos. Já uma pessoa do sexo feminino espera viver até 82/83 anos (Tabela 11). Na média de ambos os sexos, pela tábua de mortalidade do IBGE, a expectativa de vida vai até os 80 anos aos 55 anos e até os 81 anos aos 60. Pela legislação, a expectativa de sobrevida utilizada na fórmula do fator previdenciário é a mesma para ambos os sexos. Essa é uma distorção, visto que a expectativa de vida feminina é superior à masculina. Uma segunda distorção é o bônus de 5 anos no tempo de contribuição concedido às mulheres quando do cálculo do fator.

É necessário lembrar que aqueles que se aposentam por tempo de contribuição o fazem no Brasil com uma idade que, na média, é de 53 anos, como pode ser visto na Tabela 12, sendo que no caso das mulheres essa idade média por ocasião do recebimento do primeiro benefícios, é ainda inferior, de 51 anos. ${ }^{26}$ Finalmente, é necessário recordar ainda que as aposentadorias por idade representam a maior

${ }^{26}$ Esses números são similares àqueles apresentados por Delgado et al. (2006). 
parte do estoque de aposentadorias (Tabela 13) e que, nelas, na composição do estoque das aposentadorias por idade, as mulheres representam 65\%das urbanas e 61\% das rurais (Anuário Estatístico da Previdência Social, 2006). ${ }^{27}$

Table 11: Brasil - expectativa de vida atual, por idade (anos)

\begin{tabular}{|lccc|}
\hline \multicolumn{1}{|c}{ Idade } & Homens & Mulheres & Ambos os sexos \\
\hline 0 & 69 & 76 & 73 \\
10 & 71 & 78 & 75 \\
20 & 72 & 79 & 75 \\
30 & 73 & 79 & 76 \\
40 & 75 & 80 & 77 \\
50 & 77 & 81 & 79 \\
60 & 79 & 83 & 81 \\
70 & 83 & 85 & 84 \\
80 ou mais & 89 & 90 & 89 \\
\hline
\end{tabular}

: Fonte: IBGE

Table 12: INSS - Idade média na concessão da aposentadoria por tempo de contribuição: Brasil - 2006

\begin{tabular}{|lc|}
\hline Categoria & Idade média (anos) \\
\hline Homens & 54 \\
Mulheres & 51 \\
Ambos os sexos & 53 \\
\hline
\end{tabular}

: Fonte: Boletim Estatístico da Previdência Social. Vol. 12, $\mathrm{N}^{0} 02$

Table 13: Benefícios previdenciários emitidos (RGPS/INSS) (\%)/a: Brasil - 2008

\begin{tabular}{|lc|}
\hline Composição & $\%$ \\
\hline Aposentadorias & 69,7 \\
idade & 36,2 \\
invalidez & 13,7 \\
tempo de contribuição & 19,9 \\
Pensões & 30,3 \\
Total & 100 \\
\hline
\end{tabular}

: /a Exclui auxílio-doença, maternidade e outros auxílios. Dados de dezembro de 2008. Fonte: Boletim Estatístico da Previdência Social. Vol. 13, $\mathrm{N}^{\circ}$ 12.

O que se pode dizer, então, tendo em vista os resultados obtidos com os dados das tabelas mostradas nesta seção? Em primeiro lugar, podemos concluir que a alíquota de $31 \%$, ao contrário do que acontecia até a aprovação da legislação do fator previdenciário - que diminuiu o valor da aposentadoria em

${ }^{27}$ Não se deve esquecer que parcela expressiva das aposentadorias por idade do INSS é do meio rural, onde os limites para o requerimento do benefício são deduzidos em 5 anos em relação às aposentadorias por idade no meio urbano. 
relação às regras anteriormente vigentes - parece ser relativamente elevada. ${ }^{28}$ Tal conclusão é corroborada por Rocha e Caetano (2008, seção 4). Os autores mostram que o Brasil tem uma das mais elevadas alíquotas de contribuição previdenciária, embora a nossa razão de dependência de idosos seja da ordem de $8 \%$, inferior à média dos países europeus e da América Latina.

Considerando o fator previdenciário vigente, adotando uma taxa de desconto de $3 \%$ e um crescimento da renda real ao longo da vida ativa de $2 \%$ a.a., para quem começa a trabalhar aos 20 anos e tem uma expectativa de viver até os 80 anos, a alíquota atuarialmente justa deveria ser de $27,7 \%$ para as mulheres (que se aposentam com 30 anos de contribuição) e de 23,7\% para os homens (que se aposentam aos 35 anos de contribuição). ${ }^{29}$ (ver tabelas 3 e 4). Em segundo lugar, há uma diferença importante entre a situação de homens e mulheres, como já foi explicitado no exemplo citado no parágrafo acima. Também deve ser ressaltado o papel desempenhado pelo fator previdenciário. Para idades de aposentadoria mais baixas, correspondentes a menores períodos contributivos, o fator é sensivelmente inferior a 1 (ver por exemplo, a tabela 3), o que reduz o valor da aposentadoria.

Por último, os números sugerem que os requisitos atuariais parcialmente contemplados na fórmula do fator previdenciário deveriam ser também incorporados no cálculo de aposentadoria daqueles que se aposentam por idade. Ressalte-se que na Tabela 10, o fundo hipoteticamente acumulado por quem contribui durante 15 anos se esgota em 7 anos, quando o período de recebimento da aposentadoria de quem se aposenta por idade é de 15 a 20 anos, aproximadamente. Não há sistema que resista a uma situação em que uma pessoa do sexo feminino contribua com $31 \%$ do seu salário por 15 anos, aposentando-se aos 60 anos para ganhar então a aposentadoria sobre o salário de contribuição praticamente integral (a rigor correspondente a $85 \%$ dada a regra) por mais de 20 anos. Observe-se que, pela Tabela 10, uma mulher que, com os parâmetros adotados, comece a contribuir aos 40 anos para se aposentar por idade, deveria pagar uma alíquota contributiva de 53\%, muito superior aos 31\% efetivamente pagos.

\section{CONCLUSÕES}

A importância de adotar uma nova reforma da Previdência Social, que aproxime o Brasil das características observadas do sistema em outros países do mundo, é cada vez mais evidente (Pinheiro, 2004, Tafner and Giambiagi, 2007). Este artigo procurou dar subsídios para esse debate, aportando elementos técnicos que permitem aferir a adequação ou não da atual alíquota contributiva de $31 \%$, face ao que deveria ser uma situação de relativo equilíbrio atuarial entre os valores presentes das contribuições e das aposentadorias.

Os cálculos efetuados permitiram o cálculo das alíquotas necessárias para uma série de combinações de gênero, nível de escolaridade, tempo de contribuição (e, portanto, fator previdenciário), taxas de desconto e taxa de crescimento da renda de trabalhadores filiados ao RGPS. Em todos os cálculos admitiuse por hipótese que os indivíduos começam a trabalhar aos 20 anos e falecem aos 80 anos. Para os homens que trabalham por 35 anos, empregando-se uma taxa de desconto de $3 \%$, as alíquotas de contribuição variam entre $22,2 \%$ e $24,8 \%$, dependendo dos parâmetros adotados. Para as mulheres que se aposentam após 30 anos de contribuição, as alíquotas estão entre 25,3\% e 27,6\%. Também se mostrou que no caso da aposentadoria por idade os requisitos contributivos atualmente em vigor são insuficientes para custear de forma completa o benefício. Na hipótese mais favorável, o montante de con-

\footnotetext{
${ }^{28}$ Há que se lembrar, porém, que para parcela expressiva da força de trabalho, a alíquota é de fato de 28 ou $29 \%$ e não $31 \%$, uma vez que para salários até $R \$ 911,70$ a alíquota é de $8 \%$, e para salários entre $R \$ 911,71$ e R\$ 1.519,50, a alíquota é de $11 \%$. A esses valores devem ser somados ainda os $20 \%$ do empregador.

${ }^{29}$ Por outro lado, deve-se lembrar que, embora os exemplos usados indiquem a viabilidade de um equilíbrio atuarial com alíquotas menores a 31\%, os cálculos não consideram a existência de benefícios não programáveis, como são, tipicamente, o auxíliodoença ou a aposentadoria por invalidez. Em outras palavras, os cálculos pressupõem que o indivíduo contribui durante certo número de anos de forma programada e após se aposentar passa a fazer retiradas regulares. No entanto, dos quase 23 milhões de benefícios emitidos pelo RGPS (dados de dezembro de 2008) cerca de 1,7 milhão (7,5\%) são auxílios e 3,0 milhões (13,1\%) são aposentadorias por invalidez, cujo custeio não está incluído nos cálculos.
} 
tribuições efetuado equivale a somente 12 anos de recebimento, período bastante inferior ao esperado. De forma análoga, calcularam-se também as alíquotas atuarialmente necessárias para a aposentadoria por idade. Os valores encontrados vão de $33,6 \%$ a $56,7 \%$ para os homens e de $52,7 \%$ a $70,7 \%$ no caso feminino.

Embora estes valores sugiram que a alíquota de 31\% atualmente existente é razoável ou até excessiva há cinco elementos a serem considerados.

Primeiro, embora as alíquotas aqui calculadas revelem-se suficientes para cobrir os benefícios de natureza programável, particularmente a aposentadoria por tempo de contribuição, elas podem ser insuficientes para, adicionalmente, custear os benefícios de risco, não programáveis, como, por exemplo, os auxílios em caso de doença ou as aposentadorias por invalidez. E estes benefícios representam uma parcela expressiva dos gastos do INSS. Segundo, deve ser lembrado que os cálculos aqui efetuados não abarcam a concessão de pensões, que também são importante componente do dispêndio previdenciário. Terceiro, a alíquota de $31 \%$ atuarialmente equilibrada à qual o trabalho chegou no caso dos homens é maior do que a de $20 \%$ paga pelos autônomos. Quarto, que a alíquota de $31 \%$ é flagrantemente insuficiente, do ponto de vista atuarial, para os casos das pessoas que se aposentam por idade, com um período contributivo muito pequeno. Por último, para muitos trabalhadores, os de renda mais baixa, a alíquota que incide sobre sua renda é $28 \%$ e não $31 \%$.

O propósito primordial deste trabalho foi apresentar um conjunto de cálculos atuariais, para avaliar até que ponto a alíquota de $31 \%$ hoje praticada é correta e não o de inferir prescrições de políticas públicas. Entretanto, não poderíamos concluir o trabalho sem apresentar algumas recomendações evidentes que se depreendem da interpretação dos resultados alcançados:

a) É necessário caminhar no sentido de uma maior aproximação entre as regras de aposentadoria de homens e mulheres, uma vez que, do ponto de vista atuarial, o benefício concedido às mulheres na forma de um subsídio implícito pago pelo resto da sociedade, revela-se extremamente significativo. Mesmo no caso das aposentadorias por idade, no qual a incidência do fator previdenciário é opcional, a alíquota atuarial necessária para as mulheres é bastante superior à dos homens;

b) Considerando que a alíquota hoje adotada não cobre a soma do que seria uma aposentadoria combinada com o lastro para os beneficios de risco, os contribuintes deveriam pagar especificamente pelo direito a usufruir dos benefícios não programáveis;

c) É importante adotar uma providência fundamental para o equilíbrio do sistema, aumentando o período contributivo de quem se aposenta por idade, hoje limitado a apenas 14 anos e que se prevê que aumentará, mas somente até 15 anos em 2011;

d) Uma alternativa seria aumentar o período contributivo (e, por conseqüência, reduzir o tempo de recebimento do benefício). Esta política poderia futuramente gerar uma queda de alíquotas, além de implicar menor carga de transferências intergeracionais entre indivíduos, pela redução de distorções associadas às alíquotas mais elevadas.

\section{BIBLIOGRAPHY}

Anuário Estatístico da Previdência Social (2006). Ministério Da Previdência Social (AEPS).

Börsch-Supan, A. H. \& Wilke, C. B. (2003). The german public pension system: How it was, how it will be. Mannheim research institute for the economics of aging. Universität Mannheim. Discussion paper series 34-03, 2003. 
Cechin, J. (2002). Livro Branco Da Previdência Social. Ministério da Previdência e Assistência Social, Brasília.

Delgado, G., Querino, A. C., Rangel, L., \& Stivali, M. (2006). Avaliação de resultados da lei do fator previdenciário (1999-2004). IPEA. Texto para discussão, 1161.

Feldstein, M. (1995). Would privatizing social security raise economic welfare? NBER Working Paper, $\mathrm{n}$. 5281.

Feldstein, M. (2005). Structural reform of social security. NBER Working Paper, n. 11098.

Feldstein, M. \& Samwick, A. (1992). Social security rules and marginal tax rates. National Tax Journal, $45(1)$.

Feldstein, M. \& Samwick, A. (1996). The transition path in privatizing social security. NBER Working Paper, n. 5761.

Feldstein, M. \& Samwick, A. (2000). Allocating payroll tax revenue to personal retirement accounts to maintain social security benefits and the payroll tax rate. NBER Working Paper, n. 7767.

Fernandes, R. \& Gremaud, A. P. (2004). Regime de previdência dos servidores públicos: Equilíbrio financeiro e justiça atuarial. Anais do XXXII Nacional de Economia, João Pessoa, 7-10 de dezembro.

Fernandes, R. \& Narita, R. D. T. (2005). Contribuição ao INSS: Equilíbrio financeiro e imposto sobre o trabalho. Anais do XXXIII Nacional de Economia, Natal, 6-9 de dezembro.

Geanakoplos, J., Mitchell, O. S., \& Zeldes, S. P. (2000). Social security money’s worth. NBER Working Paper, n. 6722.

Giambiagi, F. (1993). Alíquota de contribuição e taxa de rentabilidade dos fundos individuais de aposentadoria: Subsídios para o debate sobre a Previdência Social. Previdência em Dados, 8(3).

Giambiagi, F., Mendonça, J. L. d. O., Beltrão, K., \& Ardeo, V. (2004). Diagnóstico da previdência social no Brasil: O que foi feito e o que falta reformar? Pesquisa e Planejamento Econômico, 34(3).

McGreevey, W., Oliveira, F. E. B. d., \& Beltrão, K. I. (1998). State-level pension reform: The case of Rio Grande do Sul. IPEA. Texto para discussão, n. 539.

Ministry of Labour and Social Affairs - MLSA, editor (2001). The Czech Pension Reform. Prepared for the ILO Conference: Occupational Pensions: Choices, Benefits and Challenges. Praga.

Oliveira, F., Beltrão, K., \& Pasinato, M. T. (1998). Proteção social e equidade: Uma proposta para o seguro social. Pesquisa e Planejamento Econômico, 28(2).

Oliveira, F. E. B. de; Beltrão, K. I. \& Maniero, L. V. F. (1997). Alíquotas equânimes para um sistema de seguridade social. IPEA. Texto para discussão, n. 524.

Ornelas, W. \& Vieira, S. P. (1999). As novas regras da previdência social. Conjuntura Econômica, 53(11).

Osorio, R. G. (2002). $1^{\circ}$ curso de capacitação no manuseio de pesquisas domiciliares. DFID/IPEA. Salvador, 10 a 21 de junho.

Pinheiro, V. (2004). Reforma da previdência: Uma perspectiva comparada. In Reformas No Brasil: Balanço e Agenda. Nova Fronteira, Rio de Janeiro. Giambiagi, F., Reis, J. G. \& Urani, A. (orgs.). 
Roach, B. \& Ackerman, F. (2005). Securing social security: Sensitivity to economic assumptions and analysis of policy options. global development and environment institute, Tufts University. Working paper, n. 05-03.

Schmaehl, W. (2002). A pension system in transition: Private pensions as partial substitute to public pensions in Germany? Trabalho apresentado no Oxford Institute of Ageing conference: Pension Security in the 21st Century: Redrawing the public-private divide. Working Paper WP602.

Souza, A. P., Zylberstajn, H., Afonso, L. E., \& Flori, P. M. (2006). Resultados fiscais da reforma de 2003 no sistema de previdência social brasileiro. Pesquisa e Planejamento Econômico, 36(1).

Stephanes, R. (1998). Reforma Da Previdência Sem Segredos. Record, Rio de Janeiro.

Tafner, P. \& Giambiagi, F. (2007). Previdência Social No Brasil: Debates, Dilemas e Escolhas. IPEA, Rio de Janeiro.

\section{A. APÊNDICE}


Table A-1: Evolução do capital acumulado (unidades monetárias)

\begin{tabular}{|c|c|c|c|c|c|}
\hline Ano & $\begin{array}{c}\text { Salário } \\
\text { de contribuição }\end{array}$ & Capital acumulado & $\begin{array}{c}\text { Ano } \\
\text { de contribuição }\end{array}$ & $\begin{array}{c}\text { Salário } \\
\text { acumulado }\end{array}$ & Capital \\
\hline 1 & 100,00 & 22,23 & 31 & 130,37 & 1247,14 \\
\hline 2 & 100,89 & 45,33 & 32 & 131,53 & 1313,80 \\
\hline 3 & 101,78 & 69,32 & 35 & 132,69 & 1382,71 \\
\hline 4 & 102,69 & 94,23 & 34 & 133,87 & 1453,96 \\
\hline 5 & 103,60 & 120,08 & 35 & 135,06 & 1527,60 \\
\hline 6 & 104,52 & 146,92 & 36 & & 1485,70 \\
\hline 7 & 105,45 & 174,77 & 37 & & 1442,55 \\
\hline 8 & 106,38 & 203,67 & 38 & & 1398,10 \\
\hline 9 & 107,33 & 233,64 & 39 & & 1352,31 \\
\hline 10 & 108,28 & 264,72 & 40 & & 1305,15 \\
\hline 11 & 109,24 & 296,95 & 41 & & 1256,58 \\
\hline 12 & 110,21 & 330,36 & 42 & & 1206,55 \\
\hline 13 & 111,19 & 364,99 & 43 & & 1155,02 \\
\hline 14 & 112,18 & 400,88 & 44 & & 1101,95 \\
\hline 15 & 113,17 & 438,07 & 45 & & 1047,28 \\
\hline 16 & 114,18 & 476,59 & 46 & & 990,97 \\
\hline 17 & 115,19 & 516,50 & 47 & & 932,97 \\
\hline 18 & 116,22 & 557,83 & 48 & & 873,23 \\
\hline 19 & 117,25 & 600,63 & 49 & & 811,70 \\
\hline 20 & 118,29 & 644,95 & 50 & & 748,33 \\
\hline 21 & 119,34 & 690,83 & 51 & & 683,05 \\
\hline 22 & 120,40 & 738,32 & 52 & & 615,82 \\
\hline 23 & 121,47 & 787,48 & 53 & & 546,56 \\
\hline 24 & 122,55 & 838,35 & 54 & & 475,23 \\
\hline 25 & 123,63 & 890,98 & 55 & & 401,76 \\
\hline 26 & 124,73 & 945,44 & 56 & & 326,09 \\
\hline 27 & 125,84 & 1001,78 & 57 & & 248,15 \\
\hline 28 & 126,96 & 1060,06 & 58 & & 167,86 \\
\hline 29 & 128,08 & 1120,34 & 59 & & 85,17 \\
\hline 30 & 129,22 & 1182,68 & 60 & & 0,00 \\
\hline
\end{tabular}

: Obs. A pessoa começa a receber a aposentadoria, no valor de 87,73 unidades monetárias, no $36^{\circ}$ ano. Fonte: Elaboração dos autores. 


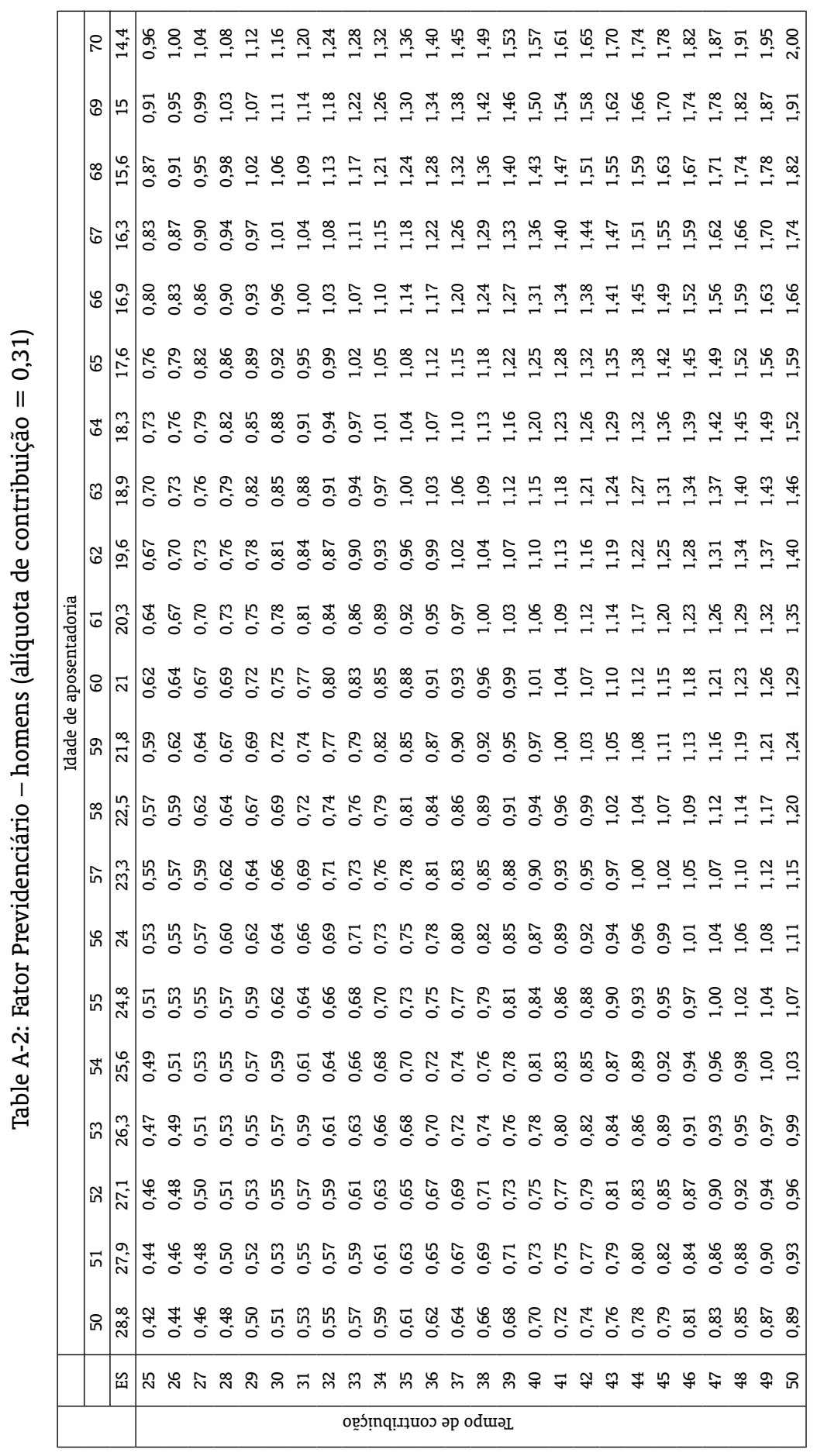

